\title{
Hippopotamyrus ansorgii species complex in the Upper Zambezi River System with a description of a new species, H. szaboi (Mormyridae)
}

Bernd Kramer, Herman Van Der Bank \& Michael Wink

Accepted 2 April 2003

\section{Introduction}

The Slender Stonebasher, Hippopotamyrus ansorgii (Boulenger, 1905), is a small mormyrid fish found in the Cuanza (Kwanza) River in Angola, and the Cunene, Okavango and Upper Zambezi Rivers in more southern parts of Africa. Isolated eastern populations inhabit the Buzi and Pungwe Rivers in Mozambique and the Ruo River (Lower Zambezi System) in Park 2006, South Africa

Kramer, B., Van der Bank, \& H., Wink, M. (2004) Hippopotamyrus ansorgii species complex in the Upper Zambezi River System with a description of a new species, H. szaboi (Mormyridae). - Zoologica Scripta, 33, 1-18.

Specimens referable to Hippopotamyrus ansorgii sampled from the Upper Zambezi River System within Caprivi (Namibia) represent a complex of three species, two of which coexist in the Upper Zambezi River, and a third that inhabits a nearby river, the Kwando, with which the Zambezi has been connected during periods of flooding. All three are indistinguishable in terms of their general appearance, but differ consistently in electric organ discharges (EOD), morphology, and molecular genetic characters. All phenotypes display a monopolar, headpositive EOD pulse with specific post- or prepotentials. For H. ansorgii from the Zambezi River (HaZ), pulse duration is less than $0.5 \mathrm{~ms}$ (down to $0.205 \mathrm{~ms} ; N=34$ ); for the syntopic H. szaboi sp. n., it is greater than $0.6 \mathrm{~ms}$ (up to $1.8 \mathrm{~ms}$ at $10 \%$ peak amplitude; $N=19$ ). The parapatric phenotype of $H$. ansorgii from the Kwando River (HaK) has pulses shorter than $0.215 \mathrm{~ms}$ (down to $0.105 \mathrm{~ms} ; N=36$ ). All three members of the species complex may be distinguished from each other by 7-9 anatomical characters, analysed by MANOVA. Based on 22 enzymes and proteins studied, the moderate to high Wright's fixation index and the significant $(P<0.05)$ allele differentiation between EOD phenotypes provide additional evidence for incipient speciation. Pairwise analyses of the three different phenotypes showed the two parapatric species of $H$. ansorgii grouped together, and distinguishable from individuals of H. szaboi. Analyses of the mitochondrial cytochrome $b$ gene revealed that all specimens which were attributed to H. szaboi form a well-supported monophyletic basal clade (bootstrap support $73 \%$ or $82 \%$ ). The genetic distances (uncorrected p distances) between $H$. szaboi and the two species of $H$. ansorgii are between $0.6 \%$ and $1.7 \%$. Within the derived $H$. ansorgii clade some phylogeographical differentiation can be seen for fishes from the Zambezi and Kwando Rivers, but the respective groups are not consistent or supported by significant bootstrap values. The question of which of the two parapatric morphological and EOD phenotypes of $H$. ansorgii recognized in the present paper represents H. ansorgii (Boulenger, 1905) cannot be resolved at present because of the paucity and unclear origin of the historical type material. Bernd Kramer, Zoologisches Institut, Universität Regensburg, D-93040 Regensburg, Germany bernd.kramer@biologie.uni-regensburg.de

Herman Van Der Bank, Zoology Department, Rand Afrikaans University, PO Box 524, Auckland

Michael Wink, Institut für Pharmazie und Molekulare Biotechnologie, Universität Heidelberg, D69120 Heidelberg, Germany

Malawi. It is found in rocky-bottomed habitats associated with fast-flowing water and regarded as rare (Bell-Cross \& Minshull 1988; Skelton 2001).

The presence of $H$. ansorgii in the Upper Zambezi River was first reported by Van der Waal \& Skelton (1984) and confirmed by Minshull (1987). While studying its electric organ discharges (EODs), two electrical phenotypes were observed 
(fig. 5.4 in Kramer 1996), associated with an inconspicuous anatomical difference (number of circumferential scales of the caudal peduncle). The two phenotypes were otherwise indistinguishable (Fig. 1A-C), apart from differences in allozyme characters (Van der Bank \& Kramer 1996).

Anatomical comparison with museum specimens (SAIAB, South African Institute for Aquatic Biodiversity, formerly RUSI, Grahamstown; P. H. Skelton, pers. comm.) identified our second morph that displays a brief EOD similar to that of $H$. ansorgii. To substantiate the validity of our suggestion of H. $s z a b o i$ as a new species we collected and analysed additional specimens of both phenotypes. While sampling from the Kwando River (which does not quite flow into the Zambezi, but which has been connected with it during brief periods of flooding) where $H$. ansorgii was thought to be absent, we recognized a third phenotype of $H$. ansorgii distinct from those of the Upper Zambezi (Fig. 1C). We also studied the new species, H. szaboi, in aquaria for several years (Scheffel 1998; Scheffel \& Kramer 2000), and provide a description below.

Other examples of using EODs to resolve systematic problems in mormyrid fish include Petrocephalus catostoma (Günther, 1866) (Kramer \& Van der Bank 2000), Marcusenius macrolepidotus (Peters, 1852) and Pollimyrus castelnaui (Kramer et al. 1998; 2003). In all cases, electrical, morphological and genetic differences supported the presence of a previously unrecognized species.

\section{Materials and methods Morphology}

Abbreviations used to represent institutions and collections cited follow Leviton et al. (1985). Specimens examined were initially identified using dichotomous keys in Bell-Cross \& Minshull (1988) and Skelton (2001), which are considered effective for fish populations occurring in Caprivi (Namibia).

Measurements used to establish morphometrics follow Fig. 2 and were made using vernier calliper readings to $0.1 \mathrm{~mm}$. Abbreviations are as follows:

BD body depth: the greatest vertical distance across the body.

CPD caudal peduncle depth: least vertical distance across caudal peduncle.

CPL caudal peduncle length: distance from end of anal fin base to midbase caudal fin.

HL head length: distance from tip of snout to furthest bony edge of the operculum.

LA length of anal fin.

LD length of dorsal fin.

LS length of snout: distance from tip of snout to posterior orbital rim of eye.

$\mathrm{Na}$ distance between pair of nares of one side (from centre to centre).

$\mathrm{nA}$ number of anal fin rays.
$\mathrm{nD}$ number of dorsal fin rays.

PAL distance from tip of snout to origin of anal fin.

$\mathrm{pD}$ distance from origin of dorsal fin to end of caudal peduncle.

PDL predorsal length: distance from tip of snout to origin of dorsal fin.

SL standard length: distance from tip of snout to midbase caudal fin.

SLS scales in lateral series (number of).

SPc scales around caudal peduncle (number of).

\section{Electric organ discharges}

EODs of each fish were recorded in the field immediately after capture in a 37-litre plastic aquarium filled with river water. This was carried out at a nearby field laboratory (except for 10 H. szaboi exported to Germany in August 1994). Conductivity changes that might have affected the EODs were excluded (Bell et al. 1976; Bratton \& Kramer 1988; Kramer \& Kuhn 1993).

Temperature $\left( \pm 0.1^{\circ} \mathrm{C}\right)$ and water conductivity $( \pm 1 \mu \mathrm{S} / \mathrm{cm})$ were constantly monitored. Fish were placed between a pair of carbon rod electrodes connected to a differential amplifier with a variable gain (up to $\times 10 ; 0.2 \mathrm{~Hz} \ldots 100 \mathrm{kHz}$; filter slopes $-3 \mathrm{~dB}$ per octave; electronics workshop, Biology Department, University of Regensburg). In the field, amplifier output was recorded by a digital storage oscilloscope (up to $10 \mathrm{MHz}$ conversion rate; amplitude resolution, 8 bit; 512 points per trace), and data transferred via digital interface. Usually eight traces per fish were recorded. In the laboratory, oscilloscope specifications are up to $100 \mathrm{MHz}$ sampling rate, 1000 points per trace, 13 bit amplitude resolution.

For analysis of EOD waveforms customized programs were used (using a software package for signal analysis, Famos v3.1). When necessary, EOD duration was corrected for $25^{\circ} \mathrm{C}$ using a $\mathrm{Q}_{10}$ value of 1.5 (Kramer \& Westby 1985) before data analysis. Fourier analysis was performed using a routine provided by Famos v3.1, on $2^{19}$ data points obtained by adding zeros to the right and left of the baseline of an EOD pulse that was centred. Frequency resolution was $\leq 0.124 \mathrm{~Hz}$, depending on A/D sampling rate (between 10 and $100 \mathrm{kHz}$ ).

Subsequent to EOD recording in the field, fish were killed by an overdose of the anaesthetic 2-phenoxy-ethanol, their standard length determined using vernier callipers, and fixed in $10 \%$ formalin for morphological studies. Some specimens were sexed by dissection and histology of the gonad. Paraffinembedded $7 \mu \mathrm{m}$ slices of the gonads were stained with Azan (Romeis 1989). Statistical analyses were carried out as indicated in Results; $P$-values are two-tailed unless otherwise stated. In the laboratory, fish were anaesthetized subsequent to EOD recording, their anatomical measurements taken, and returned to their tanks. 




$\mathbf{B}$

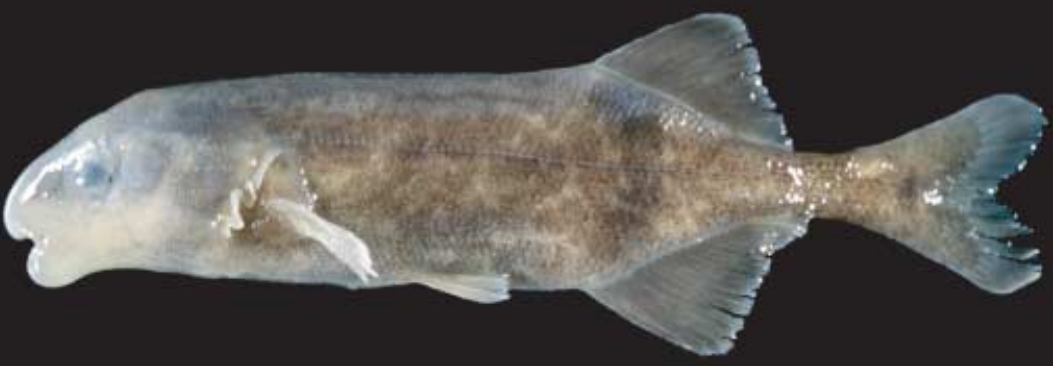

C

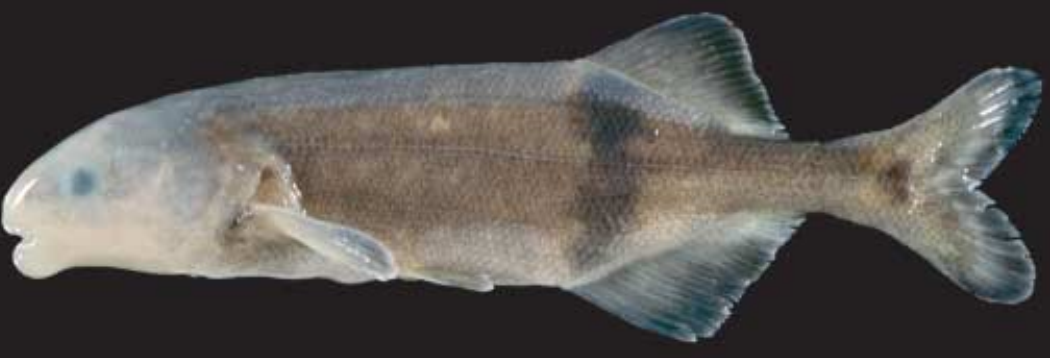

Fig. 1 A-E. -A, B. Hippopotamyrus szaboi sp. n. (14.2 cm SL, $7.2 \mathrm{~cm} \mathrm{SL})$. -C. H. ansorgii (Upper Zambezi, $\mathrm{HaZ} ; 8.8 \mathrm{~cm} \mathrm{SL})$. -D. H. ansorgii (Kwando, HaK; $6.5 \mathrm{~cm} \mathrm{SL}$ ). - E. Type specimen $(10.4 \mathrm{~cm}$ SL). All specimens fixed except A which is a live fish in an aquarium.

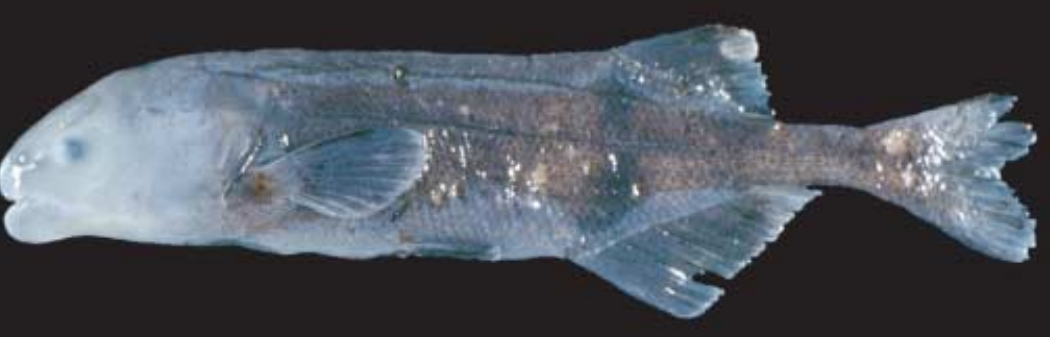

E

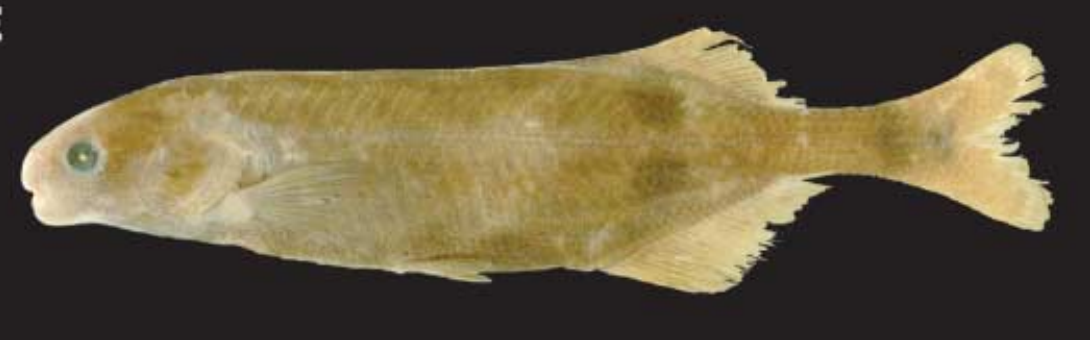




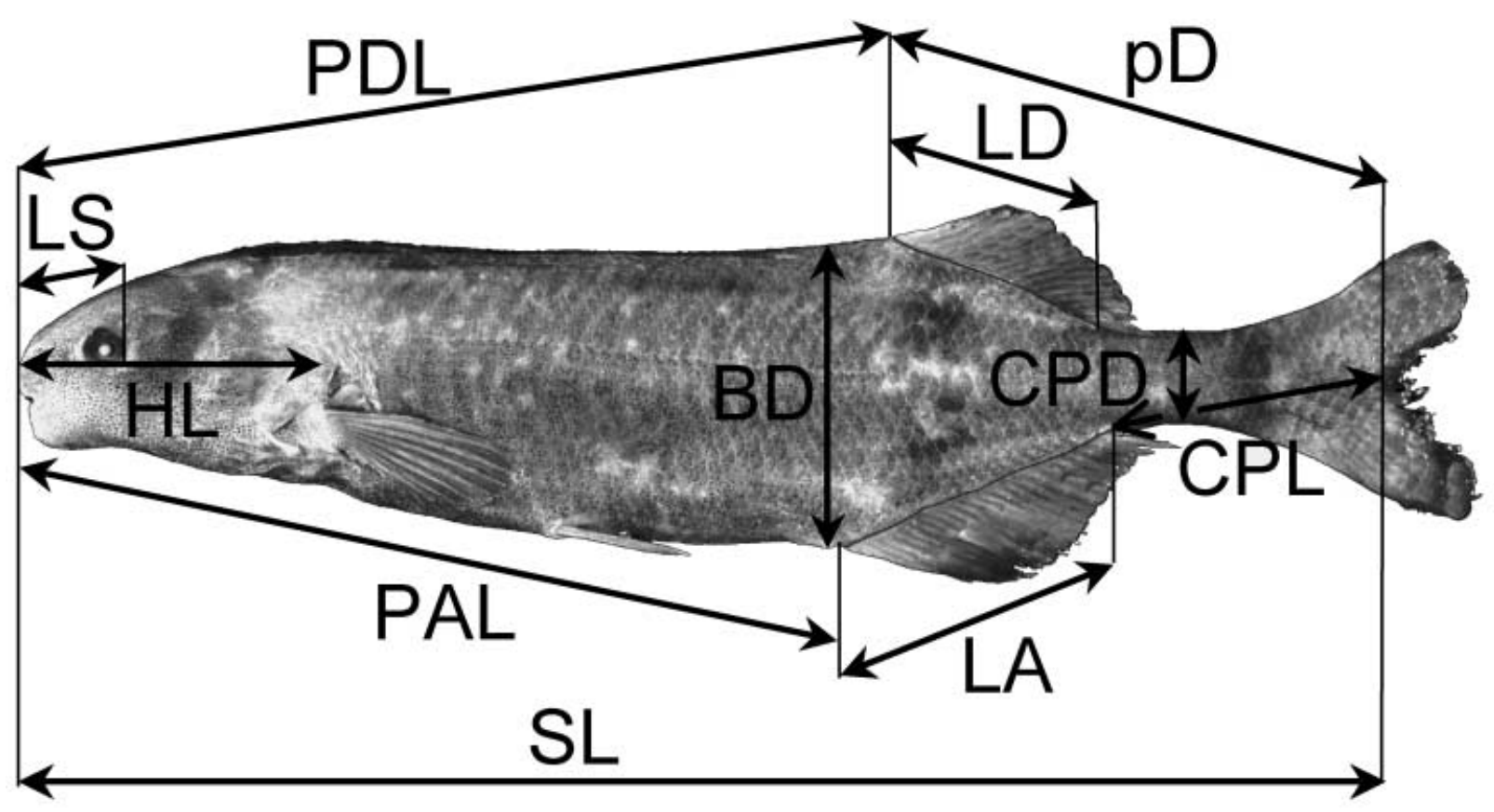

Fig. 2 Morphometrics used for the present study. Measurements are point-to-point.

Table 1 Taxa studied for allozymes, with their localities of origin and sample sizes (total in parentheses, including the individuals studied in Van der Bank and Kramer (1996)). EOD type \#2 is the new species, Hippopotamyrus szaboi

\begin{tabular}{|c|c|c|c|c|}
\hline \multicolumn{2}{|l|}{ Species } & Authority & Locality & Sample size \\
\hline \multicolumn{2}{|c|}{ Marcusenius macrolepidotus } & (Peters, 1852) & Okavango River ${ }^{1}$ & $4(12)$ \\
\hline \multicolumn{2}{|c|}{ Cyphomyrus (Hippopotamyrus) discorhynchus } & (Peters, 1852) & Zambezi River $^{2}$ & $2(12)$ \\
\hline \multicolumn{2}{|c|}{ Hippopotamyrus ansorgii complex } & (Boulenger, 1905) & & \\
\hline \multirow[t]{3}{*}{ EOD type } & $\# 1$ & & Zambezi River² & $9(18)$ \\
\hline & \#2 & & Zambezi River $^{2}$ & $6(8)$ \\
\hline & \#3 & & Kwando River ${ }^{3}$ & 16 \\
\hline
\end{tabular}

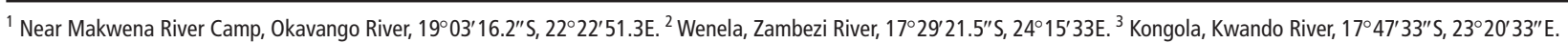

\section{Allozyme study}

Individuals from each of the three distinct types of the $H$. ansorgii complex in the Kwando and the Upper Zambezi Rivers were identified on the basis of their signal differences (Table 1). We included both Cyphomyrus discorbynchus (Peters, 1852) (previously H. discorbynchus) and Marcusenius macrolepidotus (Peters, 1852) as outgroup species; Van der Bank \& Kramer (1996) have shown that the former is more distantly related to $H$. ansorgii than the latter. Samples were stored in liquid nitrogen and transported to the laboratory. The tissue extracts were analysed by horizontal starch gel electrophoresis (12\% gels), following the buffers and procedures in Van der Bank \& Van der Bank (1995), and Van der Bank \& Kramer (1996). The allozyme data were subjected to statistical analysis using BIOSYS-2 (Swofford et al. 1997) and DISPAN (Ota 1993). $N_{\mathrm{EM}}$ values for the effective numbers of individuals exchanged between populations in each generation were calculated using the formula of Takahata (1983).

\section{PCR and DNA sequencing}

DNA was isolated from tissue samples using a proteinase $\mathrm{k}$ protocol. Isolated DNA was stored in TE buffer at $-20^{\circ} \mathrm{C}$. Cyt $b$ was amplified from total DNA under the following conditions. The $25 \mu \mathrm{l}$ reaction buffer contained $1.5 \mathrm{~mm}$ $\mathrm{MgCl}_{2}, 5 \mathrm{~mm}$ Tris, $100 \mu \mathrm{M}$ dNTPs, 0.8 units Taq polymerase (Pharmacia Biotech, Freiburg), $200 \mathrm{ng}$ DNA and 5 pmoles PCR primer (mt-FS-H 5' -TAG TTG GCC AAT GAT GAT GAT GGG TGT TCT ACT GGT T-3'; LA-FiS 5'-GTG ACT TGA AAR ACC ACC GTT G-3').

PCR was carried out initially at $94^{\circ} \mathrm{C}$ for $4 \mathrm{~min}, 31$ cycles at $94^{\circ} \mathrm{C}$ for $45 \mathrm{~s}, 52^{\circ} \mathrm{C}$ for $60 \mathrm{~s}, 72^{\circ} \mathrm{C}$ for $120 \mathrm{~s}$, and finally $72{ }^{\circ} \mathrm{C}$ for $5 \mathrm{~min}$. PCR products were stored at $4^{\circ} \mathrm{C}$ and then 




Fig. 3 Map of the study area and collection sites (arrows).

precipitated in $4 \mathrm{~mm} \mathrm{NH}_{4} \mathrm{Ac}$ and 6 vol ethanol. After centrifugation for $15 \mathrm{~min}$ at $13000 \mathrm{rpm}$, DNA pellets were washed in $70 \%$ ethanol and taken up in $10 \mu \mathrm{l}$ distilled water.

A cycle sequencing reaction (final volume $10 \mu \mathrm{l}$ ) was then carried out. Reaction buffer consisted of: $2 \mu \mathrm{l}$ reaction mix with BigDye terminators following the manufacturer's protocol (ABI Applied Biosystems), and 19 pmol primer (LAFiS, mtD 5'-AAA TCC CAT TCC ACC CCT ACT ACT CCA CAA AAG A- $3^{\prime}$ ). The sequence was 25 cycles at $96^{\circ} \mathrm{C}$ for $10 \mathrm{~s}, 52^{\circ} \mathrm{C}$ for $5 \mathrm{~s}$, and $60^{\circ} \mathrm{C}$ for $4 \mathrm{~min}$.

Sequencing products were purified by precipitation: 1 vol reaction mix, 1/10 $3 \mathrm{M} \mathrm{NaAcetate}(\mathrm{pH} 4.6), 2.5$ vol ethanol. After centrifugation for $15 \mathrm{~min}$ at $13000 \mathrm{rpm}$, DNA pellets were washed in $70 \%$ ethanol and taken up in $20 \mu$ distilled water. The purified was diluted $1: 5$ in water and applied to a 16 column automatic capillary sequencer (ABI 3100) using $50 \mathrm{~cm}$ capillaries and POP6 as a polymer.

Sequences were aligned manually and further analysed by PAUP 4.0b8 (Swofford 2001). Nucleotide sequences have been deposited with GenBank. Accession numbers are AY2369838 for H. szaboi sp. n., AY236990-4 for H. ansorgii (Upper Zambezi species, henceforth HaZ), AY236980-2, AY236989, AY236995 for $H$. ansorgii (Kwando River species, henceforth $\mathrm{HaK}$ ).

\section{Comparative material}

Hippopotamyrus ansorgii (Boulenger, 1905), syntypes BMNH no. 1905.5 .29 : 62-63(2), two specimens of 101 and $104 \mathrm{~mm}$
SL, type locality: 'Angola. Between Benguella and Bihé.' (Boulenger 1909: 74). This is the catchment area of at least three large Angolan rivers, the Cunene, Cuanza and Okavango (Fig. 3); the size of the province of Bié (modern spelling) is greater than that of Ireland. Therefore, an exact type locality cannot be established (Bell-Cross \& Minshull 1988).

ZMH 1817: two specimens of 127 and $90 \mathrm{~mm}$ SL, Rio Cukimaala near N. Lisboa (renamed Huambo in 1975), also referred to as Rio Culimaala, Cunhangama or Cunhangamua (several similar-sounding names are found on old maps due to the lack of a written orthography for the indigenous people of the region at the time; Penrith 1982), a small tributary (headwater) of the Cunene at Angola, leg. Machado, 12 May 1961. The collecting site was at $12^{\circ} 45^{\prime} \mathrm{S} 15^{\circ} 46^{\prime} \mathrm{E}$ according to P. Skelton (pers. comm.), based on Penrith (1982), at $1700 \mathrm{~m}$ altitude. Skelton believes these specimens were collected by Ladiges \& Voelker rather than Machado and that the Museum label is incorrect.

ZMH 1790: two specimens of 100 and $69 \mathrm{~mm}$ SL, Rio Cuchi in Angola, a tributary of the Kubango, no specific place given, leg. Ladiges \& Voelker, 9 October 1961.

Thirty-four specimens from the Upper Zambezi River (HaZ), East Caprivi, Namibia, SL range 37-108 mm, ZSM 29790 , 
29792-807 (17 specimens) and SAIAB 67459, 67461-4, 67467-9 (17 specimens):

(i) Four from Katima Mulilo, rocks in middle of river (opposite boat landing), approx. $17^{\circ} 29^{\prime} 30^{\prime \prime} \mathrm{S}, 24^{\circ} 16^{\prime} 18^{\prime \prime} \mathrm{E}, 11$ September 1993, water conductivity and temperature, $81 \mu \mathrm{S} /$ $\mathrm{cm}, 21.8^{\circ} \mathrm{C}$, SL from 43 to $88 \mathrm{~mm}$, at least two females.

(ii) Eight from Wenela rapids just upstream of Katima Mulilo (border post to Zambia; $17^{\circ} 29^{\prime} 21.5^{\prime \prime} \mathrm{S}, 24^{\circ} 15^{\prime} 33^{\prime \prime} \mathrm{E}$ ), 3-5 April 1996, water conductivity and temperature, $66 \mu \mathrm{S} /$ cm, $25.9^{\circ} \mathrm{C}$, SL $46-102 \mathrm{~mm}$.

(iii) Five from Wenela rapids, 9 September 1997, water conductivity and temperature, $81.6 \mu \mathrm{S} / \mathrm{cm}, 22{ }^{\circ} \mathrm{C}$, SL 58 $113 \mathrm{~mm}$

(iv) Six from Wenela rapids, 23-27 August 1999, water conductivity and temperature, $84.4 \mu \mathrm{S} / \mathrm{cm}, 22^{\circ} \mathrm{C}$, size range $37-93 \mathrm{~mm}$.

(v) Eleven from Wenela rapids, 25 January 2001, water conductivity and temperature, $81.6 \mu \mathrm{S} / \mathrm{cm}, 29.5^{\circ} \mathrm{C}$, size range $61-91 \mathrm{~mm}$.

Thirty-six specimens from the Kwando River (HaK), Caprivi Strip, Kongola (at bridge of Golden Highway, B8, crossing the Kwando), $17^{\circ} 47^{\prime} 33^{\prime \prime} \mathrm{S}, 23^{\circ} 20^{\prime} 33^{\prime \prime} \mathrm{E}$, muddy river bottom, rocks rare, no rapids, river quietly flowing through wide plain, ZSM 29773-89, 29791 (18 specimens) and SAIAB 67460, 67465-6 (18 specimens):

(i) Four specimens, 9 April 1996, water conductivity and temperature, $100 \mu \mathrm{S} / \mathrm{cm}, 25^{\circ} \mathrm{C}$, SL $34-53 \mathrm{~mm}$.

(ii) Twenty specimens, 26 August 1999, water conductivity and temperature, $236 \mu \mathrm{S} / \mathrm{cm}, 19^{\circ} \mathrm{C}$, SL $30-81 \mathrm{~mm}$.

(iii) Twelve specimens, 24 January 2001, water conductivity and temperature, $160 \mu \mathrm{S} / \mathrm{cm}, 26.6^{\circ} \mathrm{C}$, SL $55-87 \mathrm{~mm}$.

The first indication of $H$. ansorgii's presence in the Upper Zambezi (and also Okavango) was given by Ladiges (1964: 265 ), although he neglected to provide any specific geographical, anatomical or collection detail, and even the source of his information. Therefore, we regard the first documented reports to be those of Van der Waal \& Skelton (1984) and Minshull (1987). The former collected specimens from several sites of the short Namibian stretch of the Upper Zambezi between Katima Mulilo and the Zimbabwean border, the latter from the Katombora rapids, upstream of the Victoria Falls in 1982 and 1986. Specimens are preserved and stored (NMZB 4216-7). In the neighbouring, sporadically interconnected, Okavango System the presence of $H$. ansorgii was also confirmed by more recent collections (AMSA 5668; 5728; Skelton et al. 1985).

\section{Hippopotamyrus szaboi, sp. n.}

Material examined. Nineteen specimens from the Upper Zambezi River, at or near Katima Mulilo (Eastern Caprivi, Namibia), $17^{\circ} 29^{\prime} 30^{\prime \prime} \mathrm{S}, 24^{\circ} 16^{\prime} 18^{\prime \prime} \mathrm{E}$, size range $53-146 \mathrm{~mm}$
SL, caught at the same locations recorded for $\mathrm{HaK}$ in (i) to (v) above:

(i) Two specimens, 75 and $94.1 \mathrm{~mm} \mathrm{SL}, 11$ September 1993.

(ii) One specimen, $72 \mathrm{~mm} \mathrm{SL}, 4$ April 1996.

(iii) One specimen of $85 \mathrm{~mm} \mathrm{SL}, 9$ September 1997.

(iv) Five specimens, size range 53-68 mm SL, 23-27 August 1999.

(v) Ten specimens, size range $63-120 \mathrm{~mm}$ SL, 9 August 1994, Katima Mulilo, exported live to Germany. In June 1999 the largest fish measured $146 \mathrm{~mm} \mathrm{SL}$, and the smallest fish had grown from 63 to $134 \mathrm{~mm} \mathrm{SL}$.

Holotype. SAIAB $67143,9.4 \mathrm{~mm}$ SL, EOD duration at $10 \%$ peak amplitude and $25^{\circ} \mathrm{C}\left(\mathrm{T}_{10 \%}\right): 1712 \mu \mathrm{s}$, male, 11 September 1993, Upper Zambezi River, Katima Mulilo (Fig. 3), rocks in middle of river (opposite boat landing), $17^{\circ} 29^{\prime} 30^{\prime \prime} \mathrm{S}, 24^{\circ} 16^{\prime} 18^{\prime \prime} \mathrm{E}$. Coll. B. Kramer and F. H. van der Bank. Field code: 21Fish. (SAIAB, the former RUSI, JLB Smith Institute of Ichthyology at Rhodes University, Grahamstown).

Paratypes. Specimens from same sampling site as holotype: SAIAB 67144 \& (one specimen, 11 September 1993, SL $76 \mathrm{~mm}, \mathrm{~T}_{10 \%} 1330 \mu \mathrm{s}$, field code 20Fish), SAIAB 67145 (four specimens, 9 August 1994, SL 74-102 mm, $\mathrm{T}_{10 \%} 660-$ $1290 \mu$ s, field codes ansor $1 \hat{\delta}$, ansor4 $q$, ansor7 $\delta^{\lambda}$, ansor8), ZSM 29765-70 (six specimens, 9 August 1994, SL 127$147 \mathrm{~mm}, \mathrm{~T}_{10 \%} 1160-1720 \mu \mathrm{s}$, field codes ansor2, ansor 3 o,

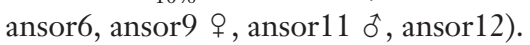

Specimens from Wenela rapids, just upstream of Katima Mulilo, $17^{\circ} 29^{\prime} 21.5^{\prime \prime} \mathrm{S}, 24^{\circ} 15^{\prime} 33^{\prime \prime} \mathrm{E}$ : SAIAB 67146 (four specimens, 23 August 1999, SL 53-67 mm, $\mathrm{T}_{10 \%} 625-1148 \mu \mathrm{s}$, field codes Wen01, Wen02, Wen13, Wen16), SAIAB 67147 (one specimen, 27 August 1999, SL $60 \mathrm{~mm}, \mathrm{~T}_{10 \%} 773 \mu \mathrm{s}$, field code Wen19), ZSM 29771 (one specimen, 3 April 1996, SL $72 \mathrm{~mm}, \mathrm{~T}_{10 \%} 1063 \mu$ s, field code Ka64), ZSM 29772 (one specimen, 9 September 1997, SL $88 \mathrm{~mm}, \mathrm{~T}_{10 \%} 1235 \mu \mathrm{s}$, field code Ven07- $-\hat{O})$.

Diagnosis. Usually 19 (18-21) dorsal fin rays, 22 (21-25) anal fin rays, 20 (17-22) scales around caudal peduncle. Proportions of SL: $5-6.2 \times$ length of dorsal fin, 4.5-5.2 $\times$ length of anal fin, 12-13.8-16.3 $\times$ caudal peduncle depth , 3.8-4.4-5 $\times$ body depth, 1.46-1.52-1.58 $\times$ predorsal length, 7.2-7.95$8.32 \times$ length of snout. Long duration of EOD (620-1800 $\mu$ s for $10 \%$ peak amplitude at $25^{\circ} \mathrm{C}$ ), simple head-negative postpotential of very weak amplitude compared to first headpositive peak and of very long duration (tens of ms). No noticeable prepotential.

Description. See Fig. 1A,B and Table 2. Head broadly rounded with a terminally positioned mouth; body long and slender, laterally compressed. Dorsal fin origin set far back 
Table 2 Morphological measures for the types of Hippotamyrus ansorgii (Boulenger, 1905), and two other museum samples of Angolan origin, and three forms of similar fish from Caprivi, as discriminated by electrical phenotype (including $\mathrm{T}_{10 \%}$, duration of EOD at $10 \%$ peak amplitude in $\mu$ s). For abbreviation of morphological characters, see Materials and methods

\begin{tabular}{|c|c|c|c|c|c|c|c|c|c|c|c|c|c|c|c|c|c|}
\hline & $\mathrm{PDL} / \mathrm{SL}$ & PAL/SL & LD/SL & LA/SL & $\mathrm{pD} / \mathrm{SL}$ & CPL/SL & CPD/CPL & LSo/HL & $\mathrm{HL} / \mathrm{SL}$ & $\mathrm{HL} / \mathrm{Na}$ & BD/SL & $\mathrm{nD}$ & $\mathrm{nA}$ & SPc & SLS & $\begin{array}{l}\mathrm{SL} \\
(\mathrm{cm})\end{array}$ & $\begin{array}{l}\mathrm{T}_{10 \%} \\
(\mu \mathrm{s})\end{array}$ \\
\hline \multicolumn{18}{|l|}{ H. szaboi } \\
\hline Mean/Median* & 0.6624 & 0.6282 & 0.1799 & 0.2097 & 0.3777 & 0.1838 & 0.3982 & 0.4824 & 0.258 & 13.68 & 0.2319 & 19 & 22 & 20 & 67 & 9.73 & 1221.7 \\
\hline Min & 0.6337 & 0.5954 & 0.1614 & 0.1936 & 0.3452 & 0.1671 & 0.3052 & 0.4494 & 0.2349 & 11.07 & 0.2018 & 18 & 21 & 17 & 61 & 5.33 & 624.7 \\
\hline Max & 0.6916 & 0.6596 & 0.1998 & 0.2222 & 0.4006 & 0.2145 & 0.4672 & 0.5203 & 0.2787 & 15.95 & 0.2651 & 21 & 25 & 22 & 73 & 14.6 & 1800 \\
\hline SE/SIQ & 0.0037 & 0.0033 & 0.0023 & 0.0021 & 0.0032 & 0.0025 & 0.0104 & 0.0047 & 0.0027 & 0.3421 & 0.0039 & 1 & 0.5 & 0 & 1.75 & 0.7045 & 79.2 \\
\hline$N$ & 19 & 19 & 19 & 19 & 19 & 19 & 19 & 19 & 19 & 18 & 19 & 19 & 19 & 19 & 12 & 19 & 19 \\
\hline \multicolumn{18}{|l|}{$\mathrm{HaZ}$} \\
\hline Mean/Median* & 0.6459 & 0.6089 & 0.1795 & 0.2104 & 0.3897 & 0.1989 & 0.3447 & 0.4927 & 0.2372 & 12.514 & 0.2208 & 19 & 22 & 16 & 66 & 7.53 & 305.3 \\
\hline Min & 0.6253 & 0.5804 & 0.1553 & 0.1912 & 0.3661 & 0.1728 & 0.2917 & 0.4583 & 0.1946 & 8.5 & 0.1942 & 15 & 20 & 16 & 58 & 3.71 & 205.5 \\
\hline $\operatorname{Max}$ & 0.6762 & 0.6384 & 0.2008 & 0.2305 & 0.4104 & 0.223 & 0.4172 & 0.5565 & 0.2604 & 15.167 & 0.2462 & 21 & 24 & 18 & 71 & 10.77 & 495.7 \\
\hline SE/SIQ & 0.002 & 0.0018 & 0.0019 & 0.0016 & 0.002 & 0.0018 & 0.0053 & 0.0043 & 0.0022 & 0.2648 & 0.0021 & 0.5 & 0.5 & 0.375 & 2 & 0.3097 & 10.95 \\
\hline$N$ & 34 & 34 & 34 & 34 & 34 & 34 & 34 & 34 & 34 & 34 & 34 & 34 & 34 & 34 & 21 & 34 & 34 \\
\hline \multicolumn{18}{|l|}{ HaK } \\
\hline Mean/Median* & 0.6584 & 0.6121 & 0.1583 & 0.1931 & 0.3771 & 0.2071 & 0.3275 & 0.4681 & 0.2498 & 11.103 & 0.214 & 18 & 22 & 16 & 67 & 5.46 & 159.8 \\
\hline Min & 0.637 & 0.5886 & 0.1346 & 0.1683 & 0.3364 & 0.1803 & 0.266 & 0.4241 & 0.2176 & 9.222 & 0.1875 & 17 & 20 & 14 & 63 & 2.96 & 105 \\
\hline $\operatorname{Max}$ & 0.6935 & 0.6409 & 0.1773 & 0.2163 & 0.4166 & 0.2242 & 0.4 & 0.5333 & 0.2972 & 13.214 & 0.2506 & 21 & 25 & 19 & 74 & 8.74 & 215.1 \\
\hline SE/SIQ & 0.0022 & 0.0019 & 0.0018 & 0.0022 & 0.0027 & 0.0019 & 0.005 & 0.0038 & 0.0031 & 0.1883 & 0.0023 & 0.5 & 0 & 0 & 1.75 & 0.2792 & 4.864 \\
\hline$N$ & 36 & 36 & 36 & 36 & 36 & 36 & 36 & 36 & 36 & 36 & 36 & 36 & 36 & 34 & 19 & 36 & 36 \\
\hline \multicolumn{18}{|l|}{ H. ansorgii, syntypes } \\
\hline Fish1 & 0.6347 & 0.599 & 0.1653 & 0.2168 & 0.3861 & 0.204 & 0.2816 & 0.4259 & 0.2139 & 12.706 & 0.1891 & 18 & 26 & 16 & 67 & 10.1 & \\
\hline Fish2 & 0.6542 & 0.6245 & 0.1772 & 0.2184 & 0.3669 & 0.1724 & 0.3944 & 0.447 & 0.2079 & 12.765 & 0.204 & 19 & 24 & 16 & 72 & 10.44 & \\
\hline Mean & 0.6444 & 0.6118 & 0.1713 & 0.2176 & 0.3765 & 0.1882 & 0.338 & 0.4365 & 0.2109 & 12.735 & 0.1966 & 18.5 & 25 & 16 & 69.5 & 10.27 & \\
\hline 1/2 Range & 0.0098 & 0.0128 & 0.0059 & 0.0008 & 0.0096 & 0.0158 & 0.0564 & 0.0105 & 0.003 & 0.03 & 0.0075 & 0.5 & 1 & 0 & 1.5 & 0.17 & \\
\hline \multicolumn{18}{|c|}{ H. ansorgii, Rio Cukimaala } \\
\hline Fish1 & 0.6378 & 0.626 & 0.1543 & 0.211 & 0.3567 & 0.1906 & 0.3554 & 0.4794 & 0.2102 & 10.68 & 0.2331 & 15 & 20 & 20 & & 12.7 & \\
\hline Fish2 & 0.6589 & 0.6534 & 0.1849 & 0.2115 & 0.3765 & 0.1905 & 0.3721 & 0.4404 & 0.2414 & 11.4737 & 0.2315 & 15 & 20 & 20 & & 9.03 & \\
\hline Mean & 0.6484 & 0.6397 & 0.1696 & 0.2113 & 0.3666 & 0.1905 & 0.3637 & 0.4599 & 0.2258 & 11.0768 & 0.2323 & 15 & 20 & 20 & & 10.86 & \\
\hline 1/2 Range & 0.0106 & 0.0137 & 0.0153 & 0.0002 & 0.0099 & 0 & 0.0084 & 0.0195 & 0.0156 & 0.3968 & 0.0008 & 0 & 0 & 0 & & 1.835 & \\
\hline \multicolumn{18}{|c|}{ H. ansorgii, Rio Cuchi } \\
\hline Fish1 & 0.6494 & 0.6106 & 0.1673 & 0.2151 & 0.3835 & 0.2082 & 0.3206 & 0.4511 & 0.2341 & 11.75 & 0.2311 & 18 & 22 & 16 & & 10.04 & \\
\hline Fish2 & 0.6618 & 0.6255 & 0.1771 & 0.2032 & 0.3948 & 0.209 & 0.3333 & 0.6552 & 0.1684 & 8.2857 & 0.2366 & 18 & 22 & 16 & & 6.89 & \\
\hline Mean & 0.6556 & 0.6181 & 0.1722 & 0.2092 & 0.3891 & 0.2086 & 0.327 & 0.5531 & 0.2012 & 10.0179 & 0.2338 & 18 & 22 & 16 & & 8.46 & \\
\hline 1/2 Range & 0.0062 & 0.0075 & 0.0049 & 0.006 & 0.0057 & 0.0004 & 0.0064 & 0.1021 & 0.0329 & 1.7321 & 0.0027 & 0 & 0 & 0 & & 1.575 & \\
\hline
\end{tabular}

*Median and SIQ (semi-interquartiles) for count measures only (nD, nA, SPc, SLS).

and behind that of anal fin, situated about two thirds of standard length from snout, obliquely orientated, anteriorly higher and posteriorly lower, and median number of rays 19 (18-21). Anal fin opposite dorsal fin but origin more anterior and also obliquely orientated, anteriorly lower and posteriorly higher, margin broadly rounded and median number of rays 22 (21-25). Scales cycloid with reticulate striae except in centre, extending anteriorly to operculum, pectoral fins and pelvic fins. SPc, median 20 (17-22). Caudal peduncle slender and subcylindrical over the entire length, usually less than a fifth SL. Tail fin with broadly rounded lobes. EOD monopolar, head-positive pulse of long duration, usually $1.22 \mathrm{~ms}$ at $25^{\circ} \mathrm{C}$ (0.62-1.8 ms), followed by a simple, weak undershoot of long duration. Dark brown or black colour with a distinctive vertical black band from dorsal origin.

Colour in preservation. See Fig. 1B. Usually dark brown or black, head lighter.

Ecology. Van der Waal \& Skelton (1984) describe H. ansorgii as 'rapid-loving' because it has not been found in any other habitat. This is confirmed by Minshull (1987). It has also been confirmed for H. szaboi in the present study. Van der Waal \& Skelton (1984) discuss rheophilic adaptations of $H$. ansorgii (reduced eye size and dark blue-grey colour). $H$. ansorgii is regarded as rare and as distinct from the majority 




Fig. 4 A-C. Oscillograms of electric organ discharges (EODs; volts over time). -A. Hippopotamyrus szaboi sp. n. -B. HaZ. -C. HaK. For each species of fish, three examples are shown that represent the within-group variability in pulse duration (from top, close to maximum, mean, and minimum). Ordinate, linear volts normalized to the same peak amplitude; head-positivity is up. Abscissa, time in $\mathrm{ms}$ as indicated by time bar (same scale throughout). EODs normalized to $25^{\circ} \mathrm{C}$ if not recorded at that temperature.

of the fish fauna in Caprivi which are characterized as inhabiting swamps and flood-plains. These comments largely also apply to $H$. szaboi. Its eyesight, however, seems good, as judged from aquarium observations.

Distribution. Presently only known from the Wenela rapids just upstream of Katima Mulilo and the rocks opposite the boat landing in Katima Mulilo (Upper Zambezi).

Relationships. Hippopotamyrus szaboi is considered closest to
$H$. ansorgii, based largely on the confusion of the identity of both species. The former is distinguished most easily by counting the number of circumferential scales of the caudal peduncle which is 20 (16 in $\mathrm{H}$. ansorgii). When compared to $H$. ansorgii ( $\mathrm{HaZ}$ and $\mathrm{HaK}), H$. szaboi has a much longerlasting EOD, and the form and duration of the usually headnegative postpotential differ strongly (Fig. 5); there is no noticeable prepotential.

Etymology. The new species is named in honour of the late Dr Thomas Szabo of the Laboratoire de Neurophysiologie Sensorielle Comparée, CNRS at Gif-sur-Yvette near Paris, one of the founding fathers of the field of electroreception (Moller et al. 1995), mentor and friend to B. K.

\section{Results}

Hippopotamyrus ansorgii (Boulenger, 1905) is a slender fish with a long body and a terminal mouth. In adults there is a vertical black band from the origin of the dorsal to the anal fin (Fig. 1). This combination of characteristics distinguishes members of the $H$. ansorgii species complex from all other southern African mormyrids. In the course of the present study, different phenotypes were initially distinguished by variant $\mathrm{EOD}$ waveforms. The question of whether or not EOD phenotypes are also morphologically distinguishable and represent genetically distinct taxa is addressed below. A comparison of our present material with the type material is necessarily limited to morphology, as in 1905 neither EOD recordings nor molecular genetic studies were possible.

\section{EODs}

The three members of our $H$. ansorgii species complex display unusual EODs for mormyrids (Kramer 1990, 1996), with a monopolar, head-positive main discharge followed by a very weak, usually head-negative postpotential (Fig. 4). The duration of the main pulse differs for each species (see below). In H. szaboi there is only a simple, usually head-negative, postpotential of very long duration (several tens of ms). It is of shorter duration and with a more complex waveform in the two H. ansorgii (2.7-4.4 ms for $\mathrm{HaZ}$; 2.0-3.6 ms for $\mathrm{HaK}$; Fig. 5). The latter is additionally distinguished by a very brief head-negative prepotential. Therefore, differences in both pulse duration and waveform distinguish the three species.

Pulse duration was determined at $10 \%$ of the peak amplitude of the head-positive main pulse (peak amplitude as measured from baseline to the peak of the discharge; $25^{\circ} \mathrm{C}$ ). The longest duration was displayed by $H$. szaboi when measured in this way $(1221.7 \mu \mathrm{s})$, and the shortest by $\mathrm{HaK}$ $(159.8 \mu \mathrm{s})$, with $\mathrm{HaZ}$ somewhere between the two (305.3 $\mu$ s; see Table 2). On average, $H$. szaboi's pulse duration was four times as long as that of $\mathrm{HaZ}$ and over seven times that of $\mathrm{HaK}$; at $10 \%$ peak amplitude, it lasted longer than $620 \mu$ s (up 

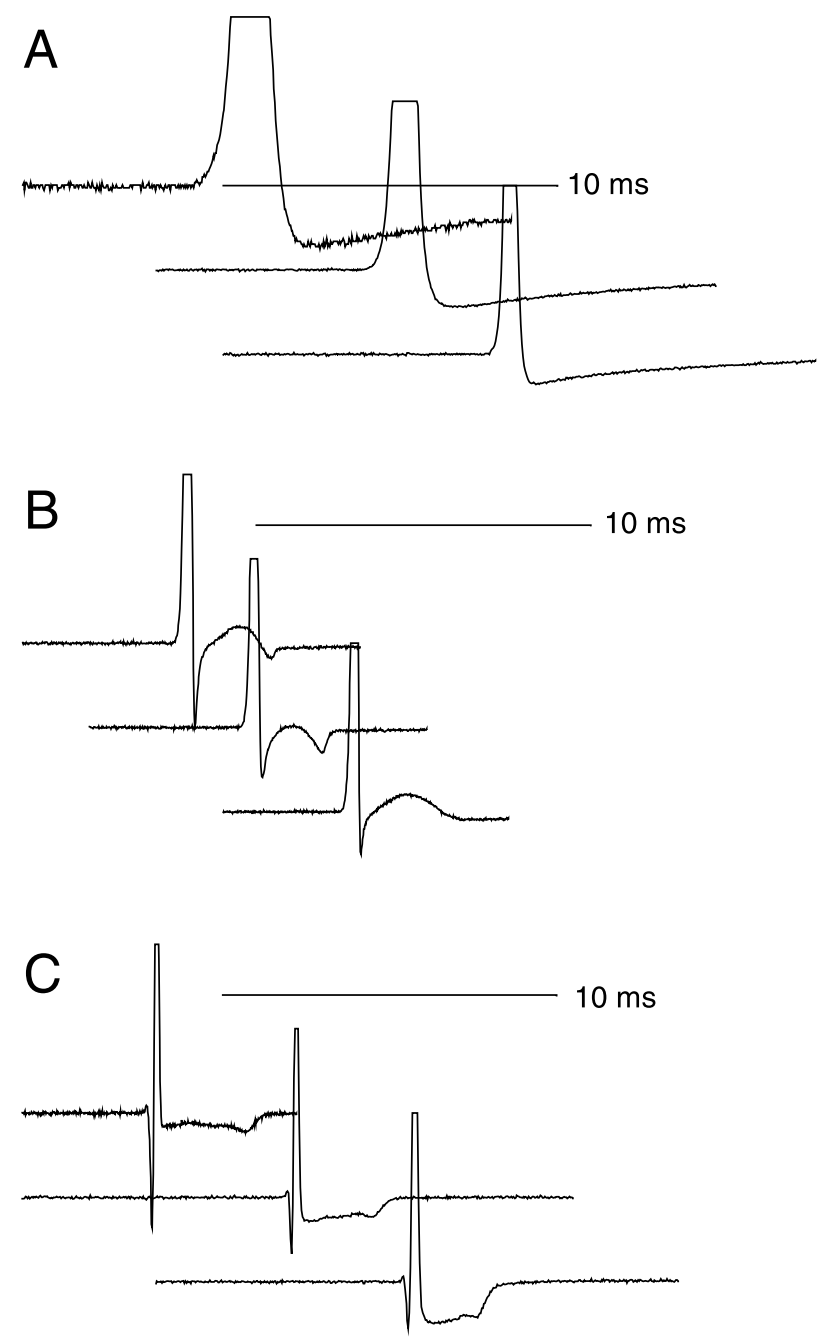

Fig. 5 A-C. -A. Hippopotamyrus szaboi. - B. HaZ. -C. HaK. EODs of three individuals of each species, amplified $3 \times$ in order to show pre- and postpotentials to the main discharge (that is clipped). Same scale throughout.

to $1800 \mu$ s) with $\mathrm{HaZ}$ lasting less than $500 \mu$ s. Between $\mathrm{HaZ}$ $(>205 \mu \mathrm{s})$ and $\mathrm{HaK}(<216 \mu \mathrm{s})$ there was virtually no overlap in pulse duration in our data.

In all three species, pulse duration is significantly correlated with size (Table 3; Fig. 6). In H. szaboi and $\mathrm{HaZ}$ there is a positive correlation, whereas it is negative in $\mathrm{HaK}$. The hypothesis that the three regression line slopes are all equal is rejected by an $F$-test $(F=9.56 ; P<0.0002)$. For HaZ and $\mathrm{HaK}$ the difference between regression line slopes is significant (Table 3), but not for H. szaboi compared with HaZ, where the lines are parallel. However, a comparison of the $Y$ intercepts reveals a statistically significant difference in pulse duration $(P<0.0001)$.
Table 3 Least-squares regression of EOD pulse duration with fish standard length, measured at $10 \%$ of peak amplitude $(\mu \mathrm{s}) . \mathrm{Hsz}=$ H. szaboi

\begin{tabular}{lccc}
\hline & Hsz & HaZ & HaK \\
\hline slope & 60.75 & 20.66 & -13.85 \\
SD & 22.35 & 5.069 & 1.813 \\
Y-intercept & 557.2 & 149.8 & 235.5 \\
SD & 228.4 & 39.2 & 10.35 \\
$r$ & 0.5505 & 0.5846 & 0.7949 \\
$P$ (slope) & 0.0146 & 0.0003 & $<0.0001$ \\
$N$ & 19 & 34 & 36 \\
\hline
\end{tabular}

SD, standard deviation. $P$ values, probability for mistakenly rejecting the null hypothesis of no correlation $[P($ slopes $)]$, or of no difference between slopes or Y-intercepts, respectively. $P$ (comparison slopes): $P$ (overall), $0.00019 ; P$ (HaZ, Hsz) n.s.; $P$ (HaZ, HaK), $<0.0001$. $P$ (comparison $Y$ intercepts): $P$ (HaZ, Hsz), $<0.0001$. n.s., not significant.

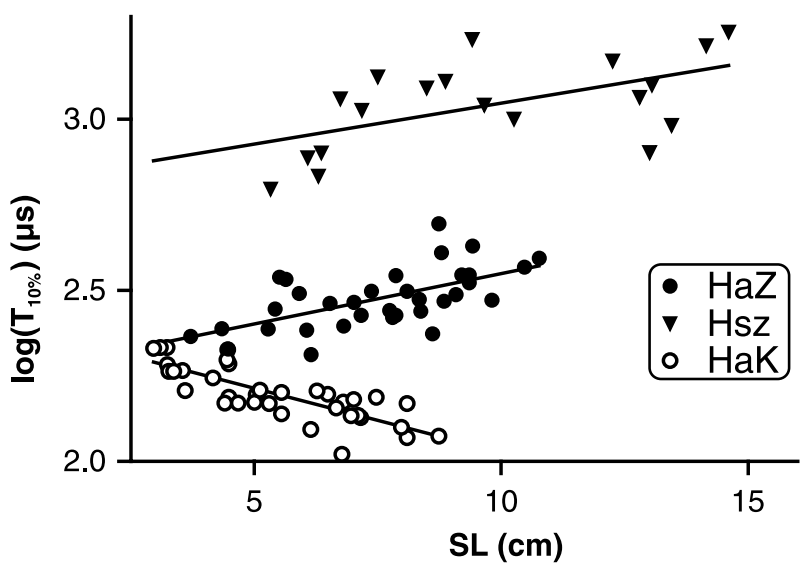

Fig. 6 Correlation between EOD pulse duration and standard length $(\mathrm{cm})$. Each point represents one individual. Ordinate, EOD pulse duration at $10 \%$ of peak amplitude (shown as logarithm, $\log \left(\mathrm{T}_{10 \%}\right)$, in $\left.\mu \mathrm{s}\right)$. The slopes of least-squares regression lines are significantly positive in $\mathrm{HaZ}(P<0.0001)$ and $\mathrm{Hsz}(H . s z a b o i$ $P<0.02)$, whereas there is a significantly negative relationship in $\mathrm{HaK}(P<0.001)$.

Amplitude spectra clearly show that in all the EODs, the spectral low-frequency range is strongest (close to DC, Fig. 7). However, there are characteristic differences in bandwidth; it is highest in $\mathrm{HaK}$ and lowest in H. szaboi (Fig. 7). Highest frequencies at $20 \mathrm{~dB}$ attenuation range from 826 to $2500 \mathrm{~Hz}$ in H. szaboi, 2750 to $7080 \mathrm{~Hz}$ in $\mathrm{HaZ}$, and 6650 to $8800 \mathrm{~Hz}$ in $\mathrm{HaK}$. The relatively small overlap among HaZ and $\mathrm{HaK}$ probably disappears in fish of sufficient size, as suggested by the regression line slopes of Fig. 6 . The size at which $H$. ansorgii reaches sexual maturity is unknown but could be $6 \mathrm{~cm}$ according to the $40 \%$ rule (Kramer 1997b) if 

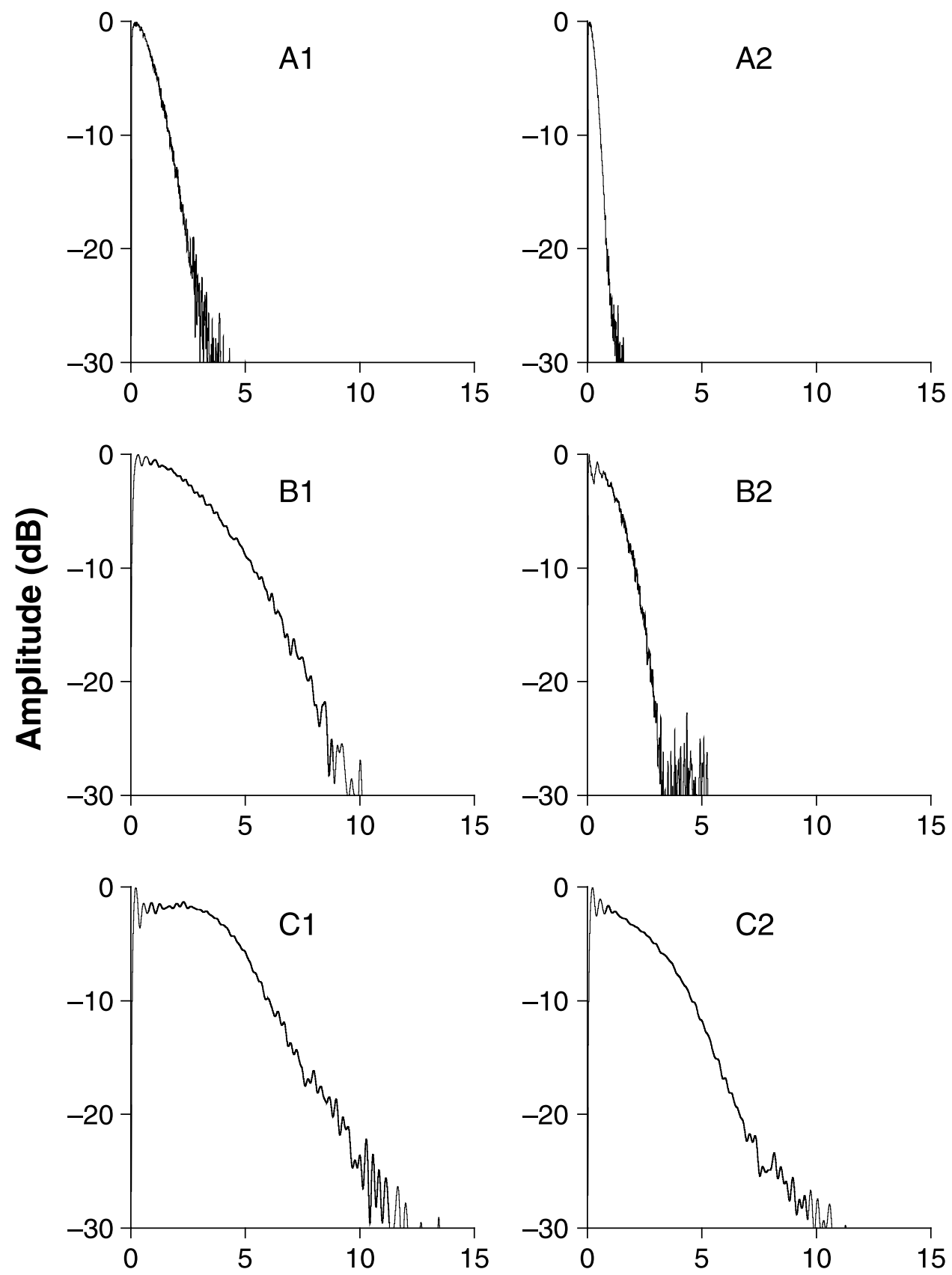

Frequency $(\mathbf{k H z})$

Fig. 7 Amplitude spectra for single EOD pulses (shortest EOD of sample, left; longest, right). A1, 2, H. szaboi sp. n. B1, 2, HaZ. C1, C2, HaK. Ordinates, amplitudes in $\mathrm{dB}$ re: strongest spectral component $=0 \mathrm{~dB}$; abscissae, frequency in $\mathrm{kHz}$. a maximum $15 \mathrm{~cm}$ SL recorded from specimens of the distant Buzi River (Bell-Cross \& Minshull 1988) also applies to our fish. At $7.6 \mathrm{~cm}$ SL a female caught in local waters during the winter appeared to be mature from gonad histology (see below). Two of our H. szaboi specimens have grown to over $14 \mathrm{~cm} \mathrm{SL}$ in the aquarium.

The EODs clearly reveal three separate taxa with regard to waveform, duration and spectral bandwidth, with additional differences between $\mathrm{HaZ}$ and $\mathrm{HaK}$ relating to the correlation of duration with size.

\section{Morphology}

Since anatomical characters taken from the same individuals tend to be interrelated, it is better to perform a single 
Table 4 Multivariate analysis of variance (MANOVA) of morphological characters of the $H$. ansorgii species complex from Caprivi. $P$ values for the probability of mistakenly rejecting the hypothesis of no difference (only values $<0.05$ shown). For means, medians, standard errors etc., see Table 2; for abbreviation of characters, Materials and methods. Hsz, $N=19$; $\mathrm{HaZ}, N=34 ; \mathrm{HaK}, N=34$

\begin{tabular}{|c|c|c|c|c|c|c|c|c|c|c|c|c|c|}
\hline & $\mathrm{PDL} / \mathrm{SL}$ & $\mathrm{PAL} / \mathrm{SL}$ & LD/SL & $\mathrm{LA} / \mathrm{SL}$ & $\mathrm{pD} / \mathrm{SL}$ & CPL/SL & CPD/CPL & $\mathrm{LS} / \mathrm{HL}$ & $\mathrm{HL} / \mathrm{SL}$ & $\mathrm{BD} / \mathrm{SL}$ & $\mathrm{nD}$ & $\mathrm{nA}$ & Spc \\
\hline MANOVA & $<0.0001$ & $<0.0001$ & $<0.0001$ & $<0.0001$ & $<0.0001$ & $<0.0001$ & $<0.0001$ & $<0.0001$ & $<0.0001$ & $<0.0001$ & $<0.0001$ & $<0.0001$ & $<0.0001$ \\
\hline $\begin{array}{l}\text { ANOVA } \\
\text { post tests* }\end{array}$ & $<0.0001$ & $<0.0001$ & $<0.0001$ & $<0.0001$ & 0.0006 & $<0.0001$ & $<0.0001$ & $<0.0001$ & $<0.0001$ & 0.001 & 0.0006 & $<0.05$ & $<0.0001$ \\
\hline $\mathrm{Hsz}, \mathrm{HaZ}$ & $<0.01$ & $<0.01$ & & & $<0.01$ & $<0.01$ & $<0.01$ & & $<0.01$ & & & & $<0.01$ \\
\hline Hsz, HaK & & $<0.01$ & $<0.01$ & $<0.01$ & & $<0.01$ & $<0.01$ & $<0.05$ & & $<0.01$ & $<0.01$ & & $<0.01$ \\
\hline $\mathrm{HaZ}$, HaK & $<0.01$ & & $<0.01$ & $<0.01$ & $<0.01$ & $<0.01$ & $<0.05$ & $<0.01$ & 0.01 & & & & \\
\hline
\end{tabular}

*Games-Howell test. MANOVA P value: same for Wilks' lambda, Roy's Greatest Root, Hotelling-Lawley Trace, and Pillai Trace tests.

multivariate analysis of variance (MANOVA) on all characters together. In this way we tested the hypothesis that the three species identifiable from their electrical phenotypes are all similar in morphology. Two characters (SLS and Na) were excluded because data sets were incomplete. SLS could not be determined in several fish because of damage from small scale-eating characins transferred to the container during sampling; with no distinctive differences present in our data, this loss appeared acceptable (Table 2). $\mathrm{Na}$, being an extremely small measure, was excluded because of the possibility of measurement errors. $\mathrm{Na}$ and SLS are, however, shown on Table 2 ( $\mathrm{Na}$ normalized as HL/Na). Unfortunately, the types had to be excluded from the MANOVA altogether because the Museum collection holds only two specimens; the same held true for the $\mathrm{ZMH}$ specimens from Angola (Table 2).

A result of $P<0.0001$ for the MANOVA clearly rejects the null hypothesis of no morphological difference among the three electrical phenotypes (Table 4), demonstrating the robustness of EOD as an independent variable. They additionally have numerous morphological differences, as shown by ANOVAs for each character performed simultaneously with the MANOVA (Table 4). Except for nA, there are significant differences in at least one of the three pairwise comparisons between phenotypes (Table 4): 7-9 anatomical characters out of the 13 tested in each comparison. Thus the three species are diagnosable by anatomical as well as EOD characters.

The most distinctive anatomical character of $H$. szaboi is the high SPc count (20) revealing no overlap with the types (16) and very little with $\mathrm{HaZ}$ and $\mathrm{HaK}$ (median also 16; Table 2). For CPD/CPL H. szaboi shows clearly higher values than $\mathrm{HaZ}$ and $\mathrm{HaK}$, including the types (testable differences, significant), and both characters may be related to the long EOD pulse duration. Similar results were found for HL/SL, with the strongest contrast between $H$. szaboi and $\mathrm{HaZ}$.

The question of which of $\mathrm{HaZ}$ and $\mathrm{HaK}$ represents the types cannot be decided conclusively due to the paucity of the type material $(N=2)$ and its unclear origin (see Material and
Methods). For some characters (e.g. LD, LA, HL, Na, nD, CPD, CPL, PDL) HaZ appears to be the better candidate, for others (e.g. LS, pD, BD) it is HaK. Not even the ZMH samples from the Cukimaala River (the type locality region) or nearby Cuchi River are clear representatives (Table 2). In fact, the former more closely resemble H. szaboi rather than $\mathrm{HaZ}$ or HaK due to their high SPc and PAL, whereas the latter agree well with the types in these characters. However, the Cukimaala specimens differ markedly from $H$. szaboi in $\mathrm{nD}$, $\mathrm{nA}$, and HL, which is not surprising given the distance and separation of river systems (Cunene and Zambezi). The Cuchi specimens resemble the types either fairly or very well in $\mathrm{SPc}, \mathrm{nD}, \mathrm{HL}, \mathrm{CPD}, \mathrm{PAL}$ (less so in $\mathrm{nA}$ ), while it is the Cukimaala specimens that better represent the types for LS, CPL, PAL. However, in the high nA count (24-26) and low BD the type material differs from the other forms of the species complex studied in the present paper, and further samples of the Museum material would be needed to separate within- and between-sampling error with certainty.

In conclusion, the type material does not seem to have been sampled from the river systems or headwaters from which material studied in the present paper originates (including the $\mathrm{ZMH}$ material from Angola). This leaves one of the numerous small coastal systems flowing from the highlands of Bié westward to the Atlantic (excluding the Cunene), or even the northward-flowing Cuanza, as a possible origin for the type material. To find this would be a daunting task even if there were no political and logistical hindrances.

\section{Gonad bistology}

A sexually dimorphic character present in many mormyrids (e.g. M. macrolepidotus, P. catostoma, and P. castelnaui), a kink of the anal fin base in the male, was absent in all fish studied. The anal fin base was straight in both sexes in all our specimens.

The sex of five male and six female $H$. szaboi was identified by removing the gonads, seven of which we examined histologically (specimen size range, $7.65-13.3 \mathrm{~cm}$ SL). Five were testes and had ripe sperm (maturity stage III in Kramer's 
1997b classification), including the two specimens killed in the field at the end of the local winter (11 September 1993 and 9 September 1997; SL 8.8 and $9.5 \mathrm{~cm})$. A female that was caught and killed on site in the field $(7.65 \mathrm{~cm}$ SL, 11 September 1993) had ripe eggs of stage V/VI (diameter $1.18 \mathrm{~mm}$ ), and thus involved in reproduction at a time when sympatric mormyrids are not similarly active (Kramer 1997b). The ovary of a female $(9.8 \mathrm{~cm} \mathrm{SL})$ killed after years in captivity held eggs of up to stage III (following the classification of Takashima \& Hibiya 1995). EOD duration in the two females was well within the male range for that size $\left(T_{10 \%}\right.$ values, 1.1 and $1.33 \mathrm{~ms}$ ), and there is no evidence for sexual dimorphism. This was also true for two more females $(12.8$ and $13.9 \mathrm{~cm}$ SL) killed in captivity with laden ovaries.

The sex of $18 \mathrm{HaZ}$ specimens killed in the field was identified by histology; 13 were female (size range, $4.3-10.2 \mathrm{~cm}$ $\mathrm{SL})$ and five male $(8.1-11.3 \mathrm{~cm} \mathrm{SL})$. Only the largest male, caught in winter (9 September 1997), was mature and fully fit for reproduction (maturity stage III); all the others, even the three caught in summer (26 January 2001) contained testes of stage II, with much less sperm and testicular canals of a narrow lumen, and many spermatid cysts. Only two females caught at the same time (6.7 and $7.4 \mathrm{~cm}$ SL, 26 January 2001) contained ripe eggs (stage VI, diameter $1.3 \mathrm{~mm}$ ) and were fit for reproduction. Most females had stage III oocytes, with three (10.2 cm SL, 3 April 1996; $8.5 \mathrm{~cm}$ and $8.2 \mathrm{~cm} \mathrm{SL,} 25$ January 2001) who had stage IV (diameter, 0.7-0.8 mm).

In $\mathrm{HaK}$ specimens sex was histologically confirmed in eight fish caught in August 1999 and January 2001. The only male (6.3 cm SL, 10 August 1999) was unfit for reproduction (stage I, with testicular canals of a narrow lumen, no sperm). Among the seven females $(6.8-9.3 \mathrm{~cm} \mathrm{SL})$ the three most mature were stage IV (oocyte diameter of $0.48 \mathrm{~mm}, 8.1-$ $9.3 \mathrm{~cm} \mathrm{SL})$.

\section{Allozyme data}

Locus abbreviations and enzyme commission numbers for the protein coding loci studied were similar to those of Van der Bank \& Kramer (1996), except for phospogluconate dehydrogenase (PGDH; E.C. 1.1.1.44). Table 5 presents allele frequencies for the three EOD waveforms. Of the 22 protein-coding loci that provided interpretable results (i.e. which showed sufficient activity and resolution for scoring), $10(45.5 \%)$ were polymorphic in one or more of the EOD types studied. Three alleles were observed at the G3PDH and $P G M$ loci in Type 3, whereas there were only two at the other polymorphic protein coding loci. EOD type 2 had the rare PROT $-1 * 105$ allele and EOD type 1 PROT $-2 * 95$. Six fixed allele differences were observed between the two outgroup species. There were four between $C$. discorbynchus and the ingroup species (compared to those of $M$. macrolepidotus at sAAT-1, LDH-B, sMEP and PEP-LT1, and three between
Table 5 Allele frequencies for three EOD waveform phenotypes within the $H$. ansorgii species complex and in two outgroup species. Abbreviations: $\mathrm{Cd}=$ Cyphomyrus discorbynchus; $\mathrm{Mm}=$ Marcusenius macrolepidotus

\begin{tabular}{|c|c|c|c|c|c|c|}
\hline & Allele & $\mathrm{Cd}$ & $\mathrm{HaZ}$ & Hsz & HaK & $\mathrm{Mm}$ \\
\hline \multirow[t]{3}{*}{$S A A T-1$} & 95 & & 1.000 & 1.000 & 1.000 & 1.000 \\
\hline & 90 & 0.950 & & & & \\
\hline & 85 & 0.050 & & & & \\
\hline \multirow{3}{*}{ EST } & 110 & & & & & 1.000 \\
\hline & 100 & & 0.500 & 0.500 & 0.786 & \\
\hline & 90 & 1.000 & 0.500 & 0.500 & 0.214 & \\
\hline \multirow[t]{3}{*}{$G 3 P D H$} & 105 & & & 0.286 & & \\
\hline & 100 & & 1.000 & 0.428 & 1.000 & \\
\hline & 90 & 1.000 & & 0.286 & & 1.000 \\
\hline \multirow{3}{*}{ GPI-A } & 100 & 1.000 & 1.000 & 0.750 & 1.000 & 0.778 \\
\hline & 95 & & & & & 0.222 \\
\hline & 92 & & & 0.250 & & \\
\hline \multirow[t]{4}{*}{$G P I-B$} & 110 & & & & & 0.900 \\
\hline & 105 & & & & & 0.100 \\
\hline & 100 & 0.917 & 1.000 & 0.750 & 1.000 & \\
\hline & 95 & 0.083 & & 0.250 & & \\
\hline \multirow[t]{3}{*}{$L D H-B$} & 110 & 1.000 & & & & \\
\hline & 105 & & & & & 0.222 \\
\hline & 100 & & 1.000 & 1.000 & 1.000 & 0.778 \\
\hline \multirow[t]{2}{*}{ sMEP } & 100 & & 1.000 & 1.000 & 1.000 & 1.000 \\
\hline & 95 & 1.000 & & & & \\
\hline \multirow[t]{3}{*}{ MPI } & 105 & 0.818 & 0.781 & 0.417 & 0.714 & 0.600 \\
\hline & 102 & 0.091 & 0.219 & 0.583 & 0.286 & 0.400 \\
\hline & 100 & 0.091 & & & & \\
\hline \multirow[t]{2}{*}{$P E P-A$} & 115 & & & & & 1.000 \\
\hline & 100 & 1.000 & 1.000 & 1.000 & 1.000 & \\
\hline \multirow[t]{2}{*}{ PEP-LT1 } & 110 & 1.000 & & & & \\
\hline & 100 & & 1.000 & 1.000 & 1.000 & 1.000 \\
\hline \multirow[t]{2}{*}{ PEP-LT2 } & 100 & 1.000 & 1.000 & 1.000 & 1.000 & 0.778 \\
\hline & 90 & & & & & 0.222 \\
\hline \multirow[t]{3}{*}{$P G D H$} & 105 & 0.833 & & & & 0.500 \\
\hline & 100 & 0.167 & 0.600 & 0.500 & & 0.500 \\
\hline & 90 & & 0.400 & 0.500 & 1.000 & \\
\hline \multirow[t]{3}{*}{$P G M$} & 120 & 1.000 & & 0.250 & & 1.000 \\
\hline & 105 & & & 0.250 & & \\
\hline & 100 & & 1.000 & 0.500 & 1.000 & \\
\hline \multirow[t]{2}{*}{ PROT-1 } & 100 & & 0.125 & 0.200 & & \\
\hline & 90 & 1.000 & 0.875 & 0.800 & 1.000 & 1.000 \\
\hline \multirow[t]{3}{*}{ PROT-2 } & 105 & & & 0.167 & & \\
\hline & 100 & 1.000 & 0.500 & 0.833 & 1.000 & 1.000 \\
\hline & 95 & & 0.500 & & & \\
\hline \multirow{4}{*}{$S S O D$} & 120 & 1.000 & & & & \\
\hline & 110 & & & & & 1.000 \\
\hline & 105 & & 1.000 & 0.750 & 1.000 & \\
\hline & 100 & & & 0.250 & & \\
\hline
\end{tabular}

M. macrolepidotus and the ingroup species (compared to those of $C$. discorbynchus at EST, GPI-B and PEP-A). The only fixed allele difference between the three genera is at $S S O D$ (Table 5). G3PDH*100, GPI- $A^{*} 100$, GPI- $B^{*} 100, P G M^{*} 100$, $P R O T-1 * 90$ and $s S O D * 105$ were present in EOD types at the highest frequency, while there were higher frequencies of 
Table 6 Nei's (1978) unbiased $D_{78}$ genetic distance coefficient and standard errors thereof below the diagonal, and $F_{\mathrm{ST}}$ (italics) and $N_{\text {EM }}$ values (bold) between the taxa studied above the diagonal.

Abbreviations: $\mathrm{Cd}=C$. discorbynchus

\begin{tabular}{lrrrr}
\hline Species/populations & \multicolumn{1}{c}{$\mathrm{Cd}$} & \multicolumn{1}{c}{$\mathrm{HaZ}$} & \multicolumn{1}{c}{$\mathrm{Hsz}$} & \multicolumn{1}{c}{ HaK } \\
\hline H. ansorgii (ZambezI) & 0.489 & & 0.129 & 0.204 \\
& $( \pm 0.169)$ & & 0.750 & 0.434 \\
H. szaboi & 0.411 & 0.037 & & 0.175 \\
& $( \pm 0.147)$ & $( \pm 0.018)$ & & 0.524 \\
H. ansorgii (Kwando) & 0.507 & 0.030 & 0.042 & \\
& $( \pm 0.176)$ & $( \pm 0.020)$ & $( \pm 0.017)$ & \\
M. macrolepidotus & 0.482 & 0.375 & 0.269 & 0.386 \\
& $( \pm 0.171)$ & $( \pm 0.144)$ & $( \pm 0.109)$ & $( \pm 0.149)$ \\
\hline
\end{tabular}

$P G D H^{*} 100$ in type 1 individuals, $M P I^{*} 102$ in type 2 and $E S T^{*} 100$ in type 3 (Table 5).

The genetic distance $D_{78}$ (Nei 1978) was calculated from the observed allele frequencies at the 22 loci (specially adapted for small sample sizes; Table 6 ). $D_{78}$ values varied from 0.030 between EOD types 1 and 3, to 0.042 between EOD types 2 and 3 (average values vary from 0.378 between the ingroup species and M. macrolepidotus to 0.472 between the EOD types and $C$. discorbynchus). Dendrograms (cophenetic correlation $=98 \%$ ) and Wagner trees (cophenetic correlation $=100 \%$ ) grouped EOD types 1 and 3 together, with $M$. macrolepidotus closer to these EOD types (bootstrap support value $=100 \%$ ) than to $C$. discorbynchus (Fig. 8). Average $F_{\mathrm{ST}}$ values were $0.129,0.175$ and 0.204 , and $N_{\mathrm{EM}}$ values 0.750 , 0.524 and 0.434 , between EOD types 1 and 2, 2 and 3, and 1 and 3 , respectively (Table 6$)$. Significant $(P<0.05)$ differences between allozyme results of the EOD types were determined using pairwise comparison. Differences between EOD types 1 and 2 were observed at seven loci, 2 and 3 at six, and 1 and 3 at three. There were also significant differences between all three pairs of EOD types $(P<0.0001$ between EOD types 1 and 2, 2 and $3, P=0.005$ between 1 and 3$)$.

\section{DNA data}

The cyt $b$ gene was amplified and sequenced from six samples of H. szaboi, six of HaZ and four of HaK. Using the sequence
Table 7 Parsimony informative characters within the H. szaboi/ ansorgii data set. $\mathrm{K}=\mathrm{Kwando}$ Z $\mathrm{Z}$ Zambesi

\begin{tabular}{lr}
\hline Input data matrix: & \\
& 24667788999 \\
Taxon/Node & 6633155522048 \\
\hline H. szaboi 15761 & ?? 336151269455 \\
H. szaboicGGTAGTC 15762 & ATACACGGTAGTC \\
H. szaboi 15763 & ATACACGGTAGTC \\
H. szaboi 15764 & ATGCACGGTAGCC \\
H. szaboi 15765 & ATGCACGGTAGCC \\
H. szaboi2 & ATACACGGTAGTC \\
H. ansorgii $9130-\mathrm{K}$ & CAGTGCAASGGTC \\
H. ansorgii $9131-\mathrm{K}$ & CAGTGCAACMGT? \\
H. ansorgii $9132-\mathrm{K}$ & CAGTGCGACGGT? \\
H. ansorgii $47-\mathrm{K}$ & ATGTGNAACAGTC \\
H. ansorgii $43-\mathrm{K}$ & ??GTGCGACGATT \\
H. ansorgii $56-\mathrm{Z}$ & ATGTGCAACAGTC \\
H. ansorgii $58-\mathrm{Z}$ & ATGTGCGACGGT \\
H. ansorgii $65-\mathrm{Z}$ & ATGTGCGGCGATC \\
H. ansorgii $66-\mathrm{Z}$ & ATGTGTGGCGGTC \\
H. ansorgii $67-\mathrm{Z}$ & ATGTGTGGGGTC \\
\hline
\end{tabular}

of $C$. discorbynchus as an outgroup, we found 115 variable sites, of which 13 were parsimony informative (Table 7).

A phylogenetic analysis using Maximum Parsimony, Neighbour Joining and Maximum Likelihood revealed that all specimens attributed to H. szaboi form a well supported monophyletic clade (bootstrap support $73 \%$ or $82 \%$ ) which clusters as a sister to $H$. ansorgii (Fig. 9). The genetic distances (uncorrected $\mathrm{p}$ distances) between $H$. szaboi and $H$. ansorgii are between 0.6 and $1.7 \%$ (Table 8 ) and clearly exceed distances found within the clusters. Within the $H$. ansorgii clade some phylogeographical differentiation can be seen, but the respective groups are not supported by significant bootstrap values.

\section{Discussion}

\section{EODs and anatomy}

Three electrical phenotypes (Figs 4-7) of specimens originally determined as $H$. ansorgii (Boulenger, 1905) when following

Fig. 8 Phenogram based on allozyme data showing the relationships between the taxa studied. Numbers at nodes are bootstraps values.




Maximum Likelihood

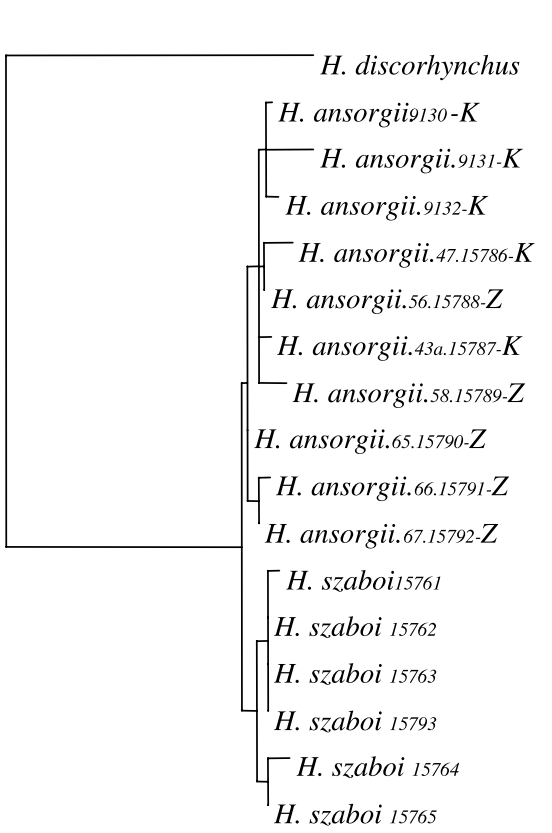

Maximum Parsimony

Bootstrap

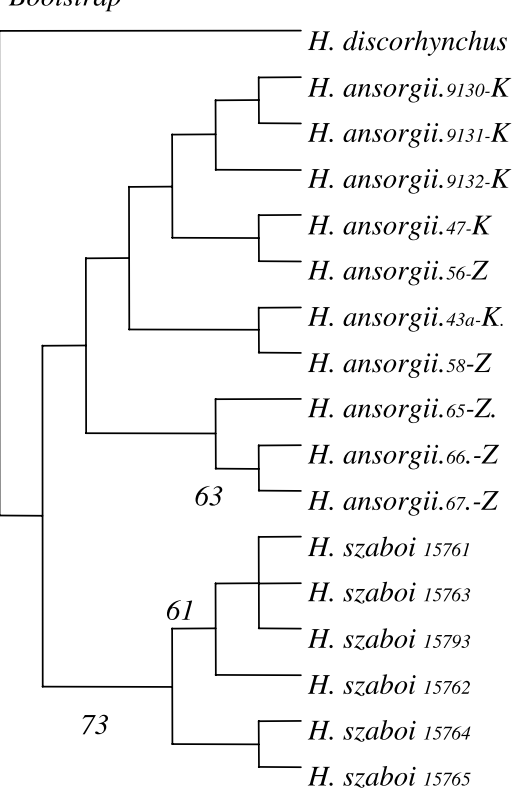

Neighbor-Joining

Bootstrap

\section{- 0.005 substitutions/site}



Fig. 9 Phylogeography of H. ansorgii and H. szaboi. Maximum Likelihood: branch lengths are correlated with genetic distances. Calculation based on number of substitution types (2), transition/transversion ratio and nucleotide frequencies estimated via ML, settings as in HKY85 model. Score of best tree 2132.76. Maximum Parsimony: bootstrap cladogram (1000 replicates); tree length 144 steps; CI = 0.931 , RI = 0.778, $\mathrm{HI}=0.069$; only bootstrap values $>60 \%$ are given. Neighbour Joining: bootstrap cladogram with Kimura 2-parameter as distance algorithm; only bootstrap values $>60 \%$ are given. Origin of $H$. ansorgii specimens: $Z=Z$ ambezi; $K=K$ wando.

current taxonomic keys, are found in the Upper Zambezi River system. Two of these (H. szaboi sp. n. and HaZ) coexist syntopically in the river while a third ( $\mathrm{HaK})$ has been found in a tributary, the Kwando. The present study shows that they are morphologically distinct (Tables 2 and 4), and that these differences are so consistent that the phenotypes are recognized as different species.

The phenotype with a long EOD pulse (H.szaboi) is morphologically most dissimilar from the types, and is therefore recognized as a new species. Based on morphological and electrical evidence, at least one more phenotype, probably $\mathrm{HaK}$, represents another new species (a name cannot be given at present, see below). HaZ rather than HaK seems to match the types fairly well in several, though not in all, anatomical characters (see Results). The question of which of these represents $H$. ansorgii (Boulenger, 1905 ) is impossible to resolve for reasons related to inadequate species description. The ZMH samples (Table 2) from rivers in the highlands of Bié in Angola demonstrate that $H$. ansorgii is also polymorphic within the type locality region (Nelson 1999), not only within the area we have studied.
In some species concepts when applied to fish, mating signals play an important role (review in Turner 1999). EOD has been shown to facilitate nocturnal courtship and mating in the mormyrid Pollimyrus adspersus (Bratton \& Kramer 1989; Crawford 1991). The EODs of the species studied here are all essentially DC but differ in post- and/ or prepotential, duration of main pulse, and spectral bandwidth, as determined by the high-frequency cutoff. The EOD of $H$. szaboi has the narrowest bandwidth (or lowest HF-cutoff), and that of $\mathrm{HaK}$ the widest. Therefore, even if these species were unable to detect the fine differences between their respective pulse waveforms (a capacity demonstrated to exist in the mormyrid P. adspersus; Graff \& Kramer 1992; Paintner \& Kramer 1998; 2003; unpublished observation) differences in bandwidth would still allow them to discriminate (additional differences in interdischarge interval patterns may be assumed to exist; for review see Kramer 1990; Scheffel \& Kramer 2000).

In none of the three species was sexual dimorphism of the waveform found (unlike M. macrolepidotus, also from Caprivi; Kramer 1997a, b). However, in each species, pulse duration was significantly correlated with SL (Fig. 6). In H. szaboi and 
Table 8 Pairwise genetic distances between the Hippopotamyrus taxa analysed. Distances are calculated as uncorrected p-distances. $1.0=100 \%$

\begin{tabular}{|c|c|c|c|c|c|c|c|}
\hline & 22 & 23 & 24 & 25 & 26 & 27 & 28 \\
\hline 22 H. ansorgii 9130 & - & & & & & & \\
\hline $23 \mathrm{H}$. ansorgii 9131 & 0.00546 & - & & & & & \\
\hline 24 H. ansorgii 9132 & 0.00441 & 0.00773 & - & & & & \\
\hline 25 H. szaboi 15761 & 0.01089 & 0.01595 & 0.01270 & - & & & \\
\hline 26 H. szaboi 15762 & 0.01131 & 0.01613 & 0.01196 & 0.00409 & - & & \\
\hline 27 H. szaboi 15763 & 0.01028 & 0.01505 & 0.01087 & 0.00307 & 0.00095 & - & \\
\hline 28 H. szaboi 15764 & 0.01233 & 0.01720 & 0.01304 & 0.00715 & 0.00472 & 0.00378 & - \\
\hline 29 H. szaboi 15765 & 0.01028 & 0.01505 & 0.01087 & 0.00511 & 0.00284 & 0.00189 & 0.00189 \\
\hline $33 \mathrm{H}$. ansorgii 47 & 0.00824 & 0.01185 & 0.00980 & 0.01126 & 0.00947 & 0.00854 & 0.01041 \\
\hline $34 \mathrm{H}$. ansorgii 43 & 0.01015 & 0.01302 & 0.00840 & 0.01697 & 0.01446 & 0.01346 & 0.01548 \\
\hline $35 \mathrm{H}$. ansorgii 56 & 0.00514 & 0.00861 & 0.00653 & 0.00920 & 0.00662 & 0.00569 & 0.00756 \\
\hline 36 H. ansorgii 58 & 0.00720 & 0.01076 & 0.00544 & 0.01125 & 0.00851 & 0.00758 & 0.00944 \\
\hline $37 \mathrm{H}$. ansorgii 65 & 0.00722 & 0.01185 & 0.00653 & 0.00935 & 0.00688 & 0.00591 & 0.00785 \\
\hline $38 \mathrm{H}$. ansorgii 66 & 0.01237 & 0.01726 & 0.01200 & 0.01332 & 0.01231 & 0.01139 & 0.01325 \\
\hline $39 \mathrm{H}$. ansorgii 67 & 0.00719 & 0.01183 & 0.00652 & 0.00919 & 0.00755 & 0.00662 & 0.00849 \\
\hline \multirow[t]{2}{*}{40 H. szaboi 2} & 0.01132 & 0.01615 & 0.01197 & 0.00409 & 0.00189 & 0.00095 & 0.00472 \\
\hline & 29 & 33 & 34 & 35 & 36 & 37 & 38 \\
\hline 29 H. szaboi 15765 & - & & & & & & \\
\hline $33 \mathrm{H}$. ansorgii 47 & 0.00851 & - & & & & & \\
\hline $34 \mathrm{H}$. ansorgii 43 & 0.01342 & 0.01138 & - & & & & \\
\hline $35 \mathrm{H}$. ansorgii 56 & 0.00567 & 0.00284 & 0.00929 & - & & & \\
\hline 36 H. ansorgii 58 & 0.00756 & 0.00663 & 0.00723 & 0.00378 & - & & \\
\hline $37 \mathrm{H}$. ansorgii 65 & 0.00589 & 0.00688 & 0.00752 & 0.00393 & 0.00393 & - & \\
\hline $38 \mathrm{H}$. ansorgii 66 & 0.01136 & 0.01139 & 0.01449 & 0.00853 & 0.00947 & 0.00689 & - \\
\hline $39 \mathrm{H}$. ansorgii 67 & 0.00661 & 0.00662 & 0.01032 & 0.00473 & 0.00472 & 0.00196 & 0.00473 \\
\hline \multirow[t]{2}{*}{40 H. szaboi 2} & 0.00284 & 0.00947 & 0.01446 & 0.00662 & 0.00851 & 0.00688 & 0.01231 \\
\hline & 39 & 40 & & & & & \\
\hline $39 \mathrm{H}$. ansorgii 67 & - & & & & & & \\
\hline 40 H. szaboi 2 & 0.00755 & - & & & & & \\
\hline
\end{tabular}

$\mathrm{HaZ}$ the growth relationship with SL was the same although absolute values differed significantly (different Y-intercepts of parallel lines, Table 3). Pulse duration for juveniles of both $\mathrm{HaZ}$ and HaK differed little, although for adults a clear difference was observed. This observation leads one to speculate whether $\mathrm{HaZ}$ and $\mathrm{HaK}$ are (or have been) sympatric or in contact with each other, perhaps due to occasional flooding of the Chobe-Linyanti-Kwando System by the Zambezi River. Therefore, character displacement (that probably played a role in the speciation of the two syntopic species) may have been a factor also for shaping the EODs of our two parapatric species of $H$. ansorgii.

\section{Genetic evidence from allozyme analyses}

Preliminary results supported an unrecognized sibling species of $H$. ansorgii in the Upper Zambezi River (Van der Bank \& Kramer 1996). However, with a larger sample size (Table 1) the assumption of a fixed allele difference was not confirmed and the sibling turned out to be an alternative homozygote (Table 5).

SOD, GPD and PGM contributed most to the differentiation between EOD Types 1 and 2, and 2 and 3. We obtained a similar result (Table 5; Fig. 8) to that reported by Van der
Bank and Kramer concerning the outgroup and ingroup taxa (C. discorbynchus is genetically more distinct from the latter than $M$. macrolepidotus).

The genetic distance $\left(D_{78}\right)$ values were all below 0.05 (Table 6) . Similar relationships (Fig. 8) were produced from $D_{78}$ (cophenetic correlation $=98 \%$ ) and the Wagner tree using Cavalli-Sforza \& Edwards' (1967) values, produced by rooting at the midpoint of the longest path (cophenetic correlation $=100 \%)$. The values were smallest between EOD types 1 and 3 (Zambezi and Kwando-Linyanti-Chobe) and largest between EOD types 1 and 2 (Zambezi); we were unable to obtain an association between geographical distance and genetic distance.

The values of Wright's (1978) fixation $(F)$ index, or inbreeding coefficient, give an indication of the chance that a gamete will unite with an identical one. This is brought about by the tendency for the accumulation in the population of the genes that are able to confer even minute selective advantages (Mayr 1970) by a process termed 'random fixation'. As time proceeds, the value of $F$ becomes larger as the homozygosity of the population increases due to inbreeding, despite selection in favour of heterozygotes (Mayr 1970; Cook 1991). The homozygous state is usually of short 
duration since the levels of genetic variability are maintained by steady gene flow (Mayr 1970). The average weighted $F_{\mathrm{ST}}$ value for the three pairs of EOD wave types is 0.169 , which is indicative of marked genetic differentiation. In the event of subspecies, the within-population component of variation will be much smaller than the between-population component (Nei 1973).

The gene diversity analysis in the present study revealed that $79.6-87.1 \%$ of total diversity originated from diversity within wave types, and $12.9-20.4 \%$ between types. There is a lack of fixed allele differences between the wave types (Table 5), but significant differences between waveforms were determined using pairwise comparison of contingency Chi-square analysis. There were significant $(P<0.05)$ differences at seven loci (G3PDH, GPI-1,-2, MPI, PGM, PROT-2 and $s S O D)$ between Types 1 and 2, six (G3PDH, GPI-1,-2, PGM, PROT-1 and $s S O D$ ) between Types 2 and 3 , and three (EST, PROT-1 and -2) between Types 1 and 3. Therefore, our new species, H. szaboi, differs to a greater extent from the two $H$. ansorgii phenotypes (Types 1 and 3). The $N_{\mathrm{EM}}$ values of 0.434-0.750 also indicate little gene flow between the ingroups to counter the effects of genetic drift. This, together with the moderate to high $F_{\mathrm{ST}}$ and significant differences between waveforms using pairwise comparison, provides evidence of recent speciation at the allozyme level.

\section{Genetic evidence from DNA analysis}

A distinct genetic lineage for $H$. szaboi is revealed by comparison of the mitochondrial cytochrome $b$ gene: individuals attributed to $H$. szaboi form a well-supported monophyletic clade that is basal to the sister clade for $H$. ansorgii ( $\mathrm{HaZ}$ and $\mathrm{HaK})$. Therefore, all other individuals of our study are derived from H. szaboi. Assuming a molecular clock of about $2 \%$ sequence divergence for mitochondrial genes over $1 \mathrm{Myr}$ (Wilson et al. 1987), the two lineages might have separated about half a million years ago.

Within the cluster for $H$. ansorgii some phylogeographical differentiation can be seen, although it is not supported by significant bootstrap values (Fig. 9). Genetic distances between the clusters for $H$. szaboi and H. ansorgii ( $\mathrm{HaZ}$ and $\mathrm{HaK}$ ) are well above those within the clusters (Table 8).

\section{Conclusions}

The genetic analyses clearly differentiate $H$. szaboi from $\mathrm{HaZ}$ and $\mathrm{HaK}$, in agreement with the conclusions from analyis of the EODs and morphology. However, $\mathrm{HaZ}$ and $\mathrm{HaK}$ cannot be differentiated from each other by genetic methods nearly as clearly as they can from $H$. szaboi, in spite of the numerous EOD and anatomical differences (Figs 4-7; Tables 2-4). In similar cases, a lack of genetic differentiation between populations has not been considered conclusive evidence against species status (see reviews by Carvalho \& Hauser 1999;
Turner 1999). Speciation between $\mathrm{HaZ}$ and $\mathrm{HaK}$ has probably occurred so recently that genes not under adaptive selection, such as those studied here, fail to show differentiation between populations, in contrast to some behavioural and morphological characters.

Electric organs in mormyrids are composed of modified skeletal muscle (Szabo 1958, 1961a,b). It is interesting to note that the EOD pulse in the basal clade, H. szaboi, also appears ancestral, corresponding to an action potential in a vertebrate skeletal muscle both in waveform and duration (1 or $2 \mathrm{~ms}$ with a simple 'undershoot' following the spike). In $\mathrm{HaZ}$ and $\mathrm{HaK}$, by contrast, the much briefer and more complex EODs with pre and/or postpotentials appear derived.

Unfortunately, Boulenger's (1905) species definition is based on only two syntypes without paratypes, and the species description cannot be improved by more samples as long as the type locality, and even the type river system, remain unknown. We agree with P.H. Skelton (pers. comm.) that it is only after the electrophysiological status of the $H$. ansorgii species-complex is known from throughout the geographical range that a true understanding of the taxonomic boundaries will emerge.

\section{Acknowledgements}

We thank Manie Grobler and Lew Scheepers (Namibian Government, Caprivi Strip) for help with specimen collection in the field. Paul Skelton (South African Institute for Aquatic Biodiversity, formerly JLB Smith Institute, Grahamstown, South Africa) provided constant support, while Glen Wagner (Katima Mulilo) was a generous host. James MacLaine and Anthony Gill (BMNH, London) and Horst Wilkens (ZMH, Hamburg) loaned type material. Hedi Sauer-Gürth carried out the cyt $b$ sequencing. Andy Scheffel and Martin Werneyer assisted with the care of specimens. Ivo Kaunzinger and Kathrin Kahler carried out the anatomical measurements and drew Fig. 2, while Brunhilde Otto provided the gonad histology and Klaus Heine (Geography Department, University of Regensburg) assisted with the preparation of the map in Fig. 3. Stefan Buchhauser photographed the fish in Fig. 1. Supported by the Deutsche Forschungsgemeinschaft (DFG).

\section{References}

Bell, C. C., Bradbury, J. \& Russell, C. J. (1976). The electric organ of a mormyrid as a current and voltage source. Fournal of Comparative Physiology A, 110, 65-88.

Bell-Cross, G. \& Minshull, J. L. (1988). The Fishes of Zimbabwe. Harare: National Museums and Monuments of Zimbabwe.

Boulenger, G. A. (1909). Catalogue of the Fresh-Water Fishes of Africa in the British Museum (Natural History), Vol. 1. London: British Museum (NH).

Bratton, B. O. \& Kramer, B. (1988). Intraspecific variability of the pulse-type discharges of the African electric fishes, Pollimyrus 
isidori and Petrocephalus bovei (Mormyridae, Teleostei), and their dependence on water conductivity. Experimental Biology, 47, 227238.

Bratton, B. O. \& Kramer, B. (1989). Patterns of the electric organ discharge during courtship and spawning in the mormyrid Pollimyrus isidori. Behavioral Ecology and Sociobiology, 24, 349-368.

Carvalho, G. R. \& Hauser, L. (1999). Molecular markers and the species concept: New techniques to resolve old disputes? Reviews in Fish Biology and Fisheries, 9, 379-382.

Cavalli-Sforza, L. L. \& Edwards, A. W. F. (1967). Phylogenetic analysis: models and estimation procedures. Evolution, 21, 550-570.

Cook, L. M. (1991). Genetic and Ecological Diversity: the Sport of Nature. London: Chapman \& Hall.

Crawford, J. D. (1991). Sex recognition by electric cues in a soundproducing mormyrid fish, Pollimyrus isidori. Brain, Behavior and Evolution, 38, 20-38.

Graff, C. \& Kramer, B. (1992). Trained weakly-electric fishes Pollimyrus isidori and Gnathonemus petersii (Mormyridae, Teleostei) discriminate between waveforms of electric pulse discharges. Ethology, 90, 279-292.

Kramer, B. (1990). Electrocommunication in Teleost Fishes: Behavior and Experiments. Berlin: Springer-Verlag.

Kramer, B. (1996). Electroreception and Communication in Fishes. Stuttgart: Gustav Fischer Verlag.

Kramer, B. (1997a). Electric organ discharges and their relation to sex in mormyrid fishes. Naturwissenschaften, 84, 119-121.

Kramer, B. (1997b). A field study of African elephantfish (Mormyridae, Teleostei): electric organ discharges in Marcusenius macrolepidotus (Peters, 1852) and Petrocephalus catostoma (Günther, 1866) as related to sex. Fournal of African Zoology, 111, 313-341.

Kramer, B. \& Kuhn, B. (1993). Electric signalling and impedance matching in a variable environment: the electric organ of a mormyrid fish actively adapts to changes in water conductivity. Naturwissenschaften, 80, 43-46.

Kramer, B., Van der Bank, F. H. \& Skelton, P. H. (1998). Two new species of snoutfish (Mormyridae) from South Africa: evidence from electric organ discharges. P. 50. PARADI Conference. Grahamstown, South Africa.

Kramer, B. \& Van der Bank, F. H. (2000). The southern churchill, Petrocephalus wesselsi, a new species of mormyrid from South Africa defined by electric organ discharges, genetics, and morphology. Environmental Biology of Fishes, 59, 393-413.

Kramer, B., Van der Bank, F. H., Wink, M., Flint, N. \& Sauer-Gürth, H. (2003). Evidence for parapatric speciation in the mormyrid fish, Pollimyrus castelnaui (Boulenger, 1911), from the Okavango - Upper Zambezi River Systems: P. marianne sp. nov., defined by electric organ discharges, morphology and genetics. Environmental Biology of Fishes, 77, 47-70.

Kramer, B. \& Westby, G. W. M. (1985). No sex difference in the waveform of the pulse type electric fish, Gnathonemus petersii (Mormyridae). Experientia, 41, 1530-1531.

Ladiges, W. (1964). Beiträge zur Zoogeographie und Ökologie der Süßwasserfische Angolas. Mitteilungen des Hamburgischen Zoologischen Museums, 61, 221-272.

Leviton, A. E., Gibbs, R. H., Heal, E. \& Dawson, C. E. (1985). Standards in herpetology and ichthyology: part I. Standard symbolic codes for institutional resource collections in herpetology and ichthyology. Copeia, 1985, 802-832.

Mayr, E. (1970). Populations, Species, and Evolution: an Abridgement of Animal Species and Evolution. Cambridge, MA: Belknap Press.
Minshull, J. L. (1987). A revised checklist of Zimbabwe fishes. Arnoldia Zimbabwe, 9 (27), 343-352.

Moller, P., Kramer, B., Serrier, J. \& Ravaille-Veron, M. (1995). Thomas Szabo (1924-1993). Brain, Behavior and Evolution, 46, 50 60.

Nei, M. (1973). Analysis of gene diversity in subdivided populations. Academy of Natural Sciences of Philadelphia, 70, 3321-3323.

Nei, M. (1978). Estimation of average heterozygosity and genetic distance from a small number of individuals. Genetics, 89, 583-590.

Nelson, J. S. (1999). Editorial and introduction: The species concept in fish biology. Reviews in Fish Biology and Fisheries, 9, 277-280.

Ota, T. (1993). DISPAN. [Computer Software and Manual]. Philadelphia: Pennsylvania State University.

Paintner, S. \& Kramer, B. (2003). Electrosensory basis for individual recognition in a weakly electric, mormyrid fish, Pollimyrus adspersus (Günther, 1866). Behavioral Ecology and Sociobiology, 55, 197-208.

Penrith, M. J. (1982). Additions to the checklist of southern African freshwater fishes and a gazetteer of south-western Angolan collecting sites. Fournal of the Limnological Society of Southern Africa, 8, $71-75$.

Romeis, B. (1989). Mikroskopische Technik, (17th edn) Böck, P, (ed.). München: Urban \& Schwarzenberg.

Scheffel, A. (1998). Elektrokommunikation im Zusammenleben dreier sympatrischer Mormyridenarten (Teleostei) aus dem Oberen Sambesi-Flußsystem (Katima Mulilo/Namibia). Doctoral Dissertation, University of Regensburg.

Scheffel, A. \& Kramer, B. (2000). Electric signals in the social behaviour of sympatric elephantfish (Mormyridae, Teleostei) from the Upper Zambezi River. Naturwissenschaften, 87, 142-147.

Skelton, P. H. (2001). A Complete Guide to the Freshwater Fishes of Southern Africa, 2nd edn. Cape Town: Struik.

Skelton, P. H., Bruton, M. N., Merron, G. S. \& van der Waal, B. C. W. (1985). The fishes of the Okavango drainage system in Angola, South West Africa and Botswana: taxonomy and distribution. Ichtyological Bulletin of the 7. L. B. Smith Institute of Ichthyology, 50, $1-21$.

Swofford, D. L. (2001). PAUP*. Phylogenetic analysis using parsimony (and other methods). Version 4.0b8. Sinauer Associates, Sunderland.

Swofford, D. L., Selander, R. B. \& Black, W. C. (1997). BIOSYS-2: a Computer Program for the Analysis of Allelic Variation in Genetics. [Computer software and manual]. Champaign, Illinois: University of Illinois at Urbana-Champaign.

Szabo, T. (1958). Structure intime de l'organe électrique de trois mormyridés. Zeitschrift für Zellforschung und Mikroskopische Anatomie, 49, 33-45.

Szabo, T. (1961a). Les organes électriques des mormyridés. In C. Chagas \& A. Paes de Carvalho (Eds) Bioelectrogenesis, pp. 20-24. Amsterdam: Elsevier.

Szabo, T. (1961b). Rapports ontogénétiques entre l'organe électrique, son innervation et sa commande encéphalique (Mormyrus rume). Zeitschrift für Zellforschung und Mikroskopische Anatomie, 55, 200-203.

Takahata, N. (1983). Gene identity and genetic differentiation of populations in the finite island models. Genetics, 104, 497-512.

Takashima, F. \& Hibiya, T. (Eds). (1995). An Atlas of Fish Histology. Normal and Pathological Features, 2nd edn. Stuttgart: Gustav Fischer Verlag.

Turner, G. F. (1999). What is a fish species? Fish Biology and Fisheries, 9, 281-297. 
Hippopotamyrus species complex from the Zambezi - B. Kramer et al.

Van der Bank, F. H. \& Kramer, B. (1996). Phylogenetic relationships between eight African species of mormyriform fish (Teleostei, Osteichthyes): resolution of a cryptic species, and reinstatement of Cyphomyrus Myers, 1960. Biochemical Systematics and Ecology, 24, 275-290.

Van der Bank, F. H. \& Van der Bank, M. (1995). An estimate of the amount of genetic variation in the snoutfish Marcusenius macrolepidotus (Peters, 1852). Water SA, 21, 265-268.
Van der Waal, B. C. W. \& Skelton, P. H. (1984). Check-list of fishes of Caprivi. Madoqua, 13 (4), 303-320.

Wilson, A. C., Ochmann, H. \& Prager, E. M. (1987). Molecular time scale for evolution. Trends in Genetics, 3, 241-247.

Wright, S. (1978). Evolution and the Genetics of Populations, Vol. 4. Variability Within and Among Natural Populations. Chicago: University of Chicago Press. 